\title{
PETROLOGIA, GEOQUÍMICA E GEOCRONOLOGIA DOS DIQUES MÁFICOS DO COMPLEXO METAMÓRFICO BONFIM SETENTRIONAL (QUADRILÁTERO FERRÍFERO) E SUAS IMPLICAÇÕES NA EVOLUÇÃO CRUSTAL DO CRATON DO SÃO FRANCISCO MERIDIONAL.
}

\author{
MAURÍCIO A. CARNEIRO*, IRNEU MENDES DE CARVALHO JÚNIOR** \& WILSON TEIXEIRA***
}

\begin{abstract}
PETROLOGY, GEOCHEMISTRY AND GEOCHRONOLOGY OF THE MAFIC DYKES FROM THE NORTHERN BONFIM METAMORPHIC COMPLEX (OUADRILÁTERO FERRÍFERO) AND THEIRIMPLICATIONS FOR THE CRUSTAL EVOLUTION OFTHE SOUTHERN SÃO FRANCISCO CRATON Four generations of mafic dykes outcrop in the Neoarchean sialic crust of the Quadrilátero Ferrífero, especially in the Northern Bonfim Metamorphic Complex. Geological data of these mafic dykes (field relations, petrology, geochemistry and geochronology) indicate distinct magmatic episodes related to different stages of tectonic evolution of the Southern São Francisco Cratòn terranes. Paraopeba and Candeias Amphibolite have Neoarchean Sm-Nd ${ }_{\mathrm{T}} \mathrm{DM}$ ) ages, but their K-Ar isotopic system was reset at the end of the Paleoproterozoic. The igneous hornblende K-Ar apparent ages indicate that emplacement of the Conceição de Itaguá Metadiabase is related to Proterozoic. These four generations of mafic dykes show geochemical affimity to withinplate tholeiite basalts, and their chemical composition is compatible with subalkaline basalts (Paraopeba Amphibolite), andesites (Candeias Amphibolite) and alkaline/trachyandesite basalt (Conceição de Itaguá Metadiabase). However, the chemical composition of the Santa alkaline/trachyandesite basalt (Conceição de Itagua Metadiabase). However, the chemical composition of the Santa than the pattern of the Conceição de Itaguá Metadiabase. Moreover, the Neoarchean mafic dykes are Ti-depleted and show negati vê $\mathrm{Ba}$ and positive $\mathrm{Nb}$ and $\mathrm{Y}$ anomalies. The geochemical criteria indicate that the magma of the Paraopeba and Candeias Amphibolite evolved from a $\mathrm{Zr} / \mathrm{Ti}$ ratio (N-MORB) mantle source depleted. Probably, because of their high $\mathrm{K} / \mathrm{P}$ and $\mathrm{Sr} / \mathrm{Rb}$ ratios, the magmas of the Paraopeba Amphibolite suffered continental contamination. As indicated by their $\mathrm{Zr} / \mathrm{Y}$ ratios, Conceição de Itaguá Metadiabase and Santa Cruz Diabase come from aTi-enriched mantle source (P-MORB). The crystallization and extraction of Ti-rich phases from this original magma led to the generation of the more evolved membcrs of these mafic dykes. Because of the preservation of their volcanic/sub-volcanic textures, the Santa Cruz Diabase must be younger and are probably related to a magmatic event occurred during the Post-Paleozoic tectonic evolution of the brazilian platform. Finally, the Northern Bonfim Metamorphic Complex mafic dykes are correlated to tectono-magmatic events occurred in the Southern São Francisco Cratòn from the Neoarchean times. Keywords: mafic dykes, Neoarchean, geochemistry, geochronology, Quadrilátero Ferrífero, Northern Bonfim Metamorphic Complex.
\end{abstract}

RESUMO Apresentam-se as relações de campo, petrologia, gcoquímica (rocha total) e geocronologia (Sm-Nd, $\mathrm{K}-\mathrm{Ar}$ ) de quatro gerações de diques máficos do Complexo Metamórfico Bonfim Setentrional, parte integrante da crosta siálica neoarqueana do Quadrilátero Ferrífero, em Minas Gerais. A colocação destes diques na crosta ocorreu sob pulsos magmáticos distintos e diacrônicos no tempo. As duas gerações mais antigas (Anfibolitos Paraopeba e Candeias) foram incorporadas ao segmento siálico ainda no Neoarqueano, conforme sugerem as relações geológicas e valores de $\mathrm{Nd}$ positivos. Posteriormente os sistemas K-Ar destes diques foram rejuvenescidos durante o Paleoproterozóico. A terceira geração (Metadiabásio Conceição de Itaguá) tem uma idade aparente K-Ar, em hornblendas ígneas relacionada ao Proterozóico. A quarta geração (Diabásio Santa Cruz), ainda não datada radiometricamente, pode estar relacionada ao Fanerozóico. Quimicamente, todas as gerações têm filiação tholeiítica e apresentam características de basaltos intraplaca. Suas composições são compatíveis com basaltos sub-alcalinos (Anfibolito Paraopeba), andesitos (Anfibolito Candeias), basalto alcalino/traquiandesito (Metadiabásio Conceição de Itaguá). A composição química das rochas do Diabásio Santa Cruz é mais variada (basaltos alcalinos a dacitos). As gerações neoarqueanas (Anfibolitos Paraopeba e Candeias) têm um padrão de REE menos fracionado que o padrão do Metadiabásio Conceicão de Itaguá e, do mesmo modo, são mais empobrecidas em Ti. Petrologicamente, o magmatismo responsável pêlos protólitos dos Anfibolitos Paraopeba e Candeias evoluiu a partir de uma fonte empobrecida na razão $\mathrm{Zr} / \mathrm{Ti}$, do tipo manto empobrecido (N-MORB). Todavia, as altas razões $\mathrm{K} / \mathrm{P}$ e $\mathrm{Sr} / \mathrm{Rb}$ do Anfibolito Paraopeba indicam que o seu magmatismo pode ter sofrido contaminação crusta! e/ou relacionar-se a uma fonte litosférica. O magmatismo responsável pelas rochas das suites Metadiabásio Conceição de Itaguá e Diabásio Santa Cruz, de acordo com as razões $\mathrm{Zr} / \mathrm{Y}$, derivou-se de uma fonte rica em $\mathrm{Ti}$, correspondendo ao manto enriquecido (P-MORB). A cristalização e a extração de fases minerais com Ti permitiu o aparecimento dos termos mais diferenciados destas suites. Apesar de não haver datação radiométrica dos Diabásio Santa Cruz, suas texturas vulcânicas/sub-vulcânicas colocam esta geração de diques em épocas mais recentes da evolução crustal da plataforma Brasileira, provavelmente relacionadas aos episódios de magmatismo máfico Mesozóico. Finalmente, a partir dos dados petrológicos, geoquímicos e geocronológicos disponíveis, correlaciona-se a colocação das diferentes gerações de magmatismo fissura! básico do Complexo Metamórfico Bonfim Setentrional com os principais eventos tectonomagmáticos que ocorreram, a partir do Neoarqueano, na porção meridional do Cratòn do São Francisco.

Palavras- chaves: Diques máficos, Neoarqueano, geoquímica, geocronologia, tectônica, Quadrilátero Ferrífero, Complexo Metamórfico Bonfim Setentrional.

INTRODUÇÃO Variadas são as descrições acerca da presença de diques máficos no Quadrilátero Ferrífero (QF; Fig. 1) e, por extensão, na porção meridional do Cratòn do São Francisco (CSFM; Teixeira et. ai. 1988, Teixeira 1989, Carneiro 1992, Oliveira \& Knauer 1993, Silva et al. 1995, Chaves \& Correia Neves 1995, Pinese et al. 1996, Pinese 1997). Muitas destas ocorrências têm sido estudadas geoquímica- e geocronologicamente, como é o caso, por exemplo, dos resultados apresentados por Couto et al. (1983), Teixeira et al. (1988), Silva et al. (1995), Pinese et al. (1996) e Pinese (1997). No estudo realizado por Teixeira et al. (1988), ficou patente uma significativa concentração de idades aparentes $\mathrm{K}$-Ar situadas por volta de $2.000 \mathrm{Ma}$, que estes autores relacionaram ao Evento Transamazônico. Mais recentemente, Pinese et al. (1996) descrevem uma suite de diques máficos, de composição gabro-norítica, na região de Lavras - Bom

* Departamento de Geologia, Escola de Minas, Universidade Federal de Ouro Preto, Morro do Cruzeiro, Ouro Preto, Minas Gerais, 35400-000, Brasil. E-mail:mauricio@degeo.ufop.br

** Departamento de Geologia, Escola de Minas, Universidade Federal de Ouro Preto, Morro do Cruzeiro, Ouro Preto, Minas Gerais, 35400-000, Brasil. PIBIC-CNPq. E-mail: irneu@em.ufop.br

*** Departamento de Geologia Geral - Instituto de Geociências - Universidade de São Paulo - C.P. 11348 - CEP 05422-970 - São Paulo - Brasil. E-mail: wteixeir@usp.br 
Sucesso - Perdões, com idade Sm-Nd da ordem de $2697 \pm 38$ Ma, relacionados, portanto, a episódios máficos/ultramáficos do Neoarqueano. Na mesma região, enxames de diques máficos de idade paleoproterozóica (associada à evolução do cinturão Mineiro) e possivelmente Mesozóica foram descritos porPinese(1997).

Diques de composição menos comum (e.g. lamprófiros; Schorscher 1991) relacionados à evolução da sequência vulcano-sedimentar do Supergrupo Rio das Velhas (SRV), também têm sido descritos na região do $\mathrm{QF}$. Todavia, é no âmbito do Complexo Metamórfico Bonfim Setentrional (CMBS; Fig. 1) que se destaca uma grande variedade de episódios máficos fissurais a partir do Neoarqueano (Carneiro 1991, Carneiro 1992, Carneiro \& Teixeira 1993, Carneiro et al. 1997, Carneiro et al. 1998). Situação similar ocorre em outras regiões cratônicas (Halls \& Fahrig 1987, Hall \& Hughes 1990, Parker et al. 1990, Baer\&Heimann 1995) e estão relacionadas a importantes episódios de rifteamento e fragmentação de supercontinentes (Ernst et al. 1995). A composição destes diques possibilita investigar a natureza da fonte mantélica e os mecanismos tectônicos que lhes dão origem. $\mathrm{O}$ presente artigo visa apresentar os dados geológicos gerais das quatro gerações de diques máficos do CMBS, discutir o seu significado petrotectônico e suas implicações na evolução tectônica CSFM.

CENÁRIO GEOLÓGICO A formação dos terrenos do CSFM (Fig. 1) teve início no Mesoarqueano, quando foram geradas as primeiras massas siálicas que hoje constituem o seu substrato (e.g., Carneiro 1992, Machado \& Carneiro 1992, Teixeira et al. | 996, Carneiro et al. 1998). Esta crosta siálica, de ampla distribuição regional, está caracterizada por uma grande diversidade petrográfica, predominantemente constituída de rochas metamórficas, subordinadamente ígneas. Também ocorre uma sequência supracrustal de natureza vulcano-sedimentar (e.g. Supergrupo Rio das Velhas - SRV) do Neoarqueano (Machado et al. 1996) e três sequências metassedimentares formadas, respectivamente, no Paleo- Mesoe Neoproterozóico (Supergrupo Minas - SM; Supergrupo Espinhaço - SE e Supergrupo São Francisco -SSF).

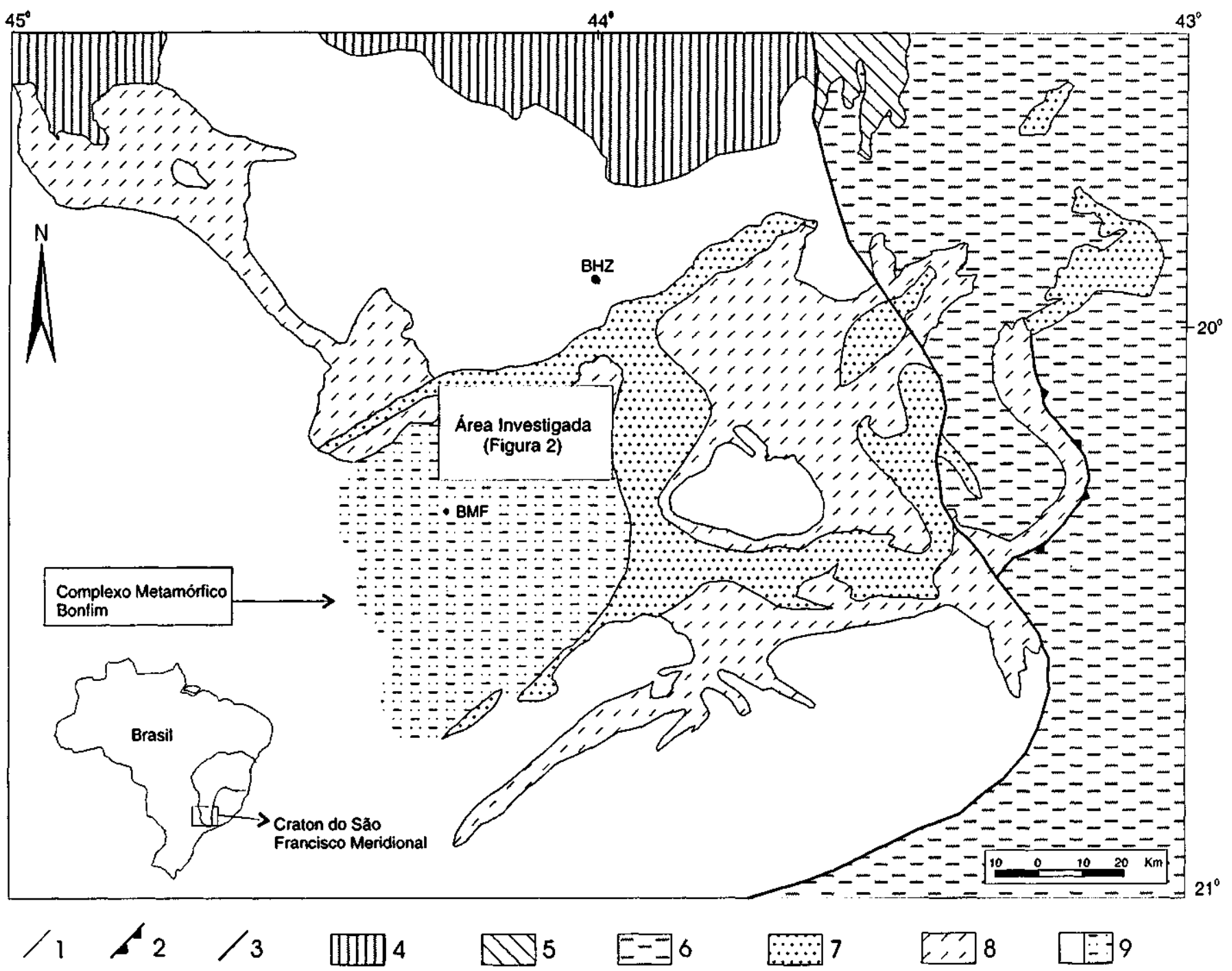

Figura l - Geologia do Craton do São Francisco Meridional (modificado de Carneiro 1992, Carneiro et al 1997). Símbolos: $l$ - Contato geológico; 2 - Empurrão; 3 - Limite cratônico oriental; 4 - Supergrupo São Francisco; 5 -Supergrupo Espinhaço; 6 Complexo M etamórfico formado ou retrabalhado no Neoproterozóico; 7 - Supergrupo Minas; 8 -Supergrupo Rio das Velhas; 9 - Complexo Metamórfico Arqueano. BHZ - Belo Horizonte; B FM - Bonfim.

Figure l - Geology ofthe Soulhern São Francisco Craton (after Carneiro 1992, Carneiro et al. J 997). Keys: l -Geological contact; 2 - Thrust fault; 3 - Eastern cralonic boundary; 4 - São Francisco Supergroup; 5 - Espinhaço Supergroup; 6 - Metamorphic Complex fonned or reworked in the Neoproterozoic; 7 - Minas Supergroup; 8 - Rio das Velhas Supergroup; 9 - Archean Metamorphic Complex. Cities: BHZ-Belo Horizonte, BFM - Bonfim. 
As ocorrências mais significativas do SRV e do SM localizam-se na parte oriental da figura 1 , onde está situado o QF. Ramificações para norte, noroeste e sudoeste compreendem, regionalmente, domínios residuais sugestivos de uma distribuição pretérita mais abrangente. O SE expõe-se a partir da porção nordeste do CSFM (Fig. 1), com amplas exposições a norte. O SSF representa a cobertura sedimentar cratônica exposta ao longo da extremidade norte da figura 1, delimitando, neste trajeto, os setores setentrional e ocidental do Complexo Metamórfico do CSFM. Este é limitado, a leste, sul e sudoeste, por faixas de dobramento constituídas por complexos metamórficos gerados ou retrabalhados no Neoproterozóico.

O CMBS (Fig. 2) é um dos fragmentos da crosta siálica do CSFM, cuja evolução geológica teve início ainda no Mesoarqueano (Carneiro 1992, Carneiro et al. 1997* Machado \& Carneiro 1992, Teixeira et al. 1996, Carneiro et al. 1998). Este complexo, assim como outros do QF (e.g. Complexo Metamórfico Belo Horizonte, Bação, Caeté, etc.), constituem o substrato siálico das sequências supracrustais. De acordo com Carneiro (1992), o CMBS é constituído por oito unidades litoestratigráficas informais (Tabela 1), das quais as seis mais antigas foram geradas e/ou retrabalhadas no Neoarqueano, a sétima está relacionada ao Neoproterozóico e a oitava, provavelmente, ao Fanerozóico. Destas oito unidades, quatro são félsicas e demais são máficas (Tabela 1) e estão representadas por quatro gerações de diques.

\section{DIQUES MÁFICOS DO COMPLEXO METAMÓR-} FICO BONFIM SETENTRIONAL: CARACTERÍSTICAS DE CAMPO, PETROLOGIA E GEOCRONOLOGIA Anfibolito Paraopeba Segundo Carneiro (1992) as rochas da suite denominada de Anfibolito Paraopeba (AP) são oriundas do mais antigo episódio máfico fissural do CMBS. Os diques desta geração têm orientação de NNW a NNE, e afloram como intrusões rompidas e boudins exclusivamente nos domínios da suíte Gnaisse Alberto Flores (GAF), cuja idade mínima ${ }^{207} \mathrm{~Pb}^{206} \mathrm{~Pb}$, em zircão é da ordem $2920 \mathrm{Ma}$ (Machado \& Carneiro 1992, Tabela 1). A geocronologia $\mathrm{Rb}-\mathrm{Sr}$ e K-Ar das unidades litoestratigráficas do CMBS (Tabela 1) refletem aparentes distúrbios isotópicos causados por sucessivos episódios de soerguimento do segmento meridional do Craton do São Francisco no decorrer de sua evolução do Neoarqueano ao Neoproterozóico. As rochas da suíte AP têm uma idade inferida arqueanacom base no cálculo do valor de $\varepsilon_{\mathrm{Nd}}$ para $\mathrm{T}=2780 \mathrm{Ma}(+0,6$; Tabela 2$)$. Pelo método K-Ar, a partir de concentrados de hornblenda, foram obtidas idades aparentes entre 2160 e $1930 \mathrm{Ma}$, sugerindo uma superposição metamórfica durante o ciclo Transamazônico (Tabela 3).

As rochas da suite AP são melanocráticas, faneríticas, cqüigranulares médias e muito foliadas. Quando localizadas em zonas de cisalhamento, adquirem um aspecto xistoso, com substituição da hornblenda por biotita. A sua textura varia de nematoblástica a granonematoblástica, dada pela alternância de leitos com hornblenda e com plagioclásio, em cristais subédricos a anédricos poligonizados e com junções tríplices. A paragênese principal é constituída de hornblenda com pleocroísmo verde oliva a castanho médio, plagioclásio e proporções bastante reduzidas de quartzo.

Uma característica bastante comum da hornblenda destas rochas é uma variação composicional marginal, notada a partir de uma gradação de cor em luz natural de um anfibólio de mais alto grau, como hornblenda castanha, para um de grau mais baixo, verde claro (actinolita ?). O plagioclásio está praticamente todo alterado (saussuritizado) para uma associação de sericita + clorita + epídoto + clinozoizita, indicando médio a baixo grau. A titanita (leucoxênio) é um acessório frequente, e ocorre em agregados de grãos anédricos nas bordas dos opacos, ou como cristais mais desenvolvidos, embora anédricos, associados à hornblenda. Os opacos são geralmente anédricos e possuem aspecto corroído. Apatita e o zircão são acessórios raros e ocorrem como pequenos cristais prismáticos.

Anfibolito Candeias A segunda geração de diques máficos do CMBS é representada pelas rochas da suíte denominada de Anfibolito Candeias (AC). Os diques desta geração têm orientação NNE. Um fato notável é a sua associação com o Tonalito Samambaia (TS), datado pelo método U-Pb em zircão e titanita em $2779 \pm 3 \mathrm{Ma}$ (Tabela 1; Carneiro 1992, Machado \& Carneiro 1992). Esses diques sistemati-

Tabela l - Características petrográficas e geocronológicas das unidades litoestratigráficas do Complexo Metamórfico Bonfim Setentrional.

Table J-Petrographic and geochnmological characterisitics ofthe lithostragraphic uniisfrom the Northern Bonfim Metainorphic Complex.

\begin{tabular}{|c|c|c|c|c|}
\hline \multirow{2}{*}{$\begin{array}{c}\text { Unidades } \\
\text { Litoestratigráficas } \\
\text { do CMIBS } \\
\end{array}$} & \multirow[b]{2}{*}{ Características Petrografiteas Gerais } & \multicolumn{3}{|c|}{ Idade (Ma) } \\
\hline & & $\mathrm{U}-\mathrm{Pb}^{\prime}(\mathrm{Ma})$ & Sin-Nd (T & $\mathrm{Rb}-\mathrm{Sr}^{3}(\mathrm{WR})^{\hat{6}}$ \\
\hline Diabśsio Santa Cruz (DSC) & $\begin{array}{l}\text { Enxames de diques máficos com lexturas igneas preservadas } \\
\text { cortando as unidades mais vilhas. }\end{array}$ & - & - & - \\
\hline $\begin{array}{l}\text { Metadiabásio Conceiç̧̃̄o de } \\
\text { ltaguá (MCI) }\end{array}$ & $\begin{array}{l}\text { Enxames de diques máficos ou pequenos "stocks" e bossas, com } \\
\text { texturas ignteas preservadas, contando as tunidades mais velhas e o } \\
\text { Supergrupo Minas. }\end{array}$ & - & & - \\
\hline Granito Brumadinho (GB) & $\begin{array}{l}\text { Pequemos corpos e diques cortando o bandamento gaaíssico das } \\
\text { rochas da suifte } \mathbf{G A F} \text {. }\end{array}$ & $\begin{array}{l}2703+24 /-20 \\
\text { (Zircko) }\end{array}$ & $\begin{array}{l}3100(\varepsilon(t)=-2,7) \\
2940(\varepsilon(t)=-1,0)\end{array}$ & $\begin{array}{c}982 \pm 91 \\
R_{1}=0,741 \pm 0,002 \\
M S W D=10,3\end{array}$ \\
\hline Anfibolito Candeias (AC) & $\begin{array}{l}\text { Diques míficos com blastofenocristais de plagioclásio e } \\
\text { homblenda poiquitobtástica, intrusivos nas unidades anteriores, } \\
\text { especialmente, no TS. }\end{array}$ & - & - & $=$ \\
\hline Tonalito Samambaia (TS) & $\begin{array}{l}\text { Granilóides cinzentos com texturas ígneas preservadas e } \\
\text { intrusjos nas rochas dos suítes GSN e GAF. }\end{array}$ & $\begin{array}{l}2778+3 /-2 \\
\text { (Zirçio e Titanita) }\end{array}$ & $\begin{array}{l}3090(\varepsilon(t)=-2.5) \\
2940(\varepsilon(t)=-0,9)\end{array}$ & $\begin{array}{c}1188 \pm 46 \\
R_{0}=0,713 \pm 0,0005 \\
M S W D=24,9\end{array}$ \\
\hline Gnaisse Souza Noschese (GSN) & $\begin{array}{l}\text { Orto-gnaisses cinzentos cotn fotiaçto milonitica bem } \\
\text { desenvolvida, intrusivos nas rochas da sufite } G \Lambda \mathrm{F} \text {. }\end{array}$ & & $3240(\varepsilon(t)=-1,7)$ & $\begin{array}{c}1295 \pm 80 \\
R_{b}=1,006 \pm 0,017 \\
M S W D=7,9\end{array}$ \\
\hline Anfibolito Paraopeba (AP) & $\begin{array}{l}\text { Diques maificos boudinados e rompidos com textura } \\
\text { granonematoblastica encontrados dentro das rochas da suíte GAF. }\end{array}$ & - & $\cdot$ & - \\
\hline Gnaisse Alberto Flores (GAF) & $\begin{array}{l}\text { Gnaisses cinzentos de composiţăo trondhjemítica. É a uridade } \\
\text { litoestratigráfica ou suíte metamórfica mais antiga do Complexo } \\
\text { Metamórfico Bonfim Setentrional (CNHS). }\end{array}$ & $\begin{array}{l}2772 \pm 6^{2} \\
2920^{3} \\
\text { (Zirctuo) }\end{array}$ & $3150(\varepsilon(t)=-2,4)$ & $\begin{array}{c}2219 \pm 80 \\
R_{10}=0,707 \pm 0,601 \\
M S W D=2, J\end{array}$ \\
\hline
\end{tabular}

Machado \& Carneiro (1992); ${ }^{2}$ Sobrecrescimento $;{ }^{3}$ Núcleo. ${ }^{4}$ Idades $\mathrm{T}_{\mathrm{DM}}$ (Teixeira et al. 1996) recalculadas com base nos parâmetros isotópicos de DePaolo (1981). Ver apêndice para

detalhes e valores de $\varepsilon(\mathrm{t})$ calculados para as idades $\mathrm{T}_{\mathrm{DM}},{ }^{5}$ Carneiro $(1992),{ }^{6}$ Isócrona 


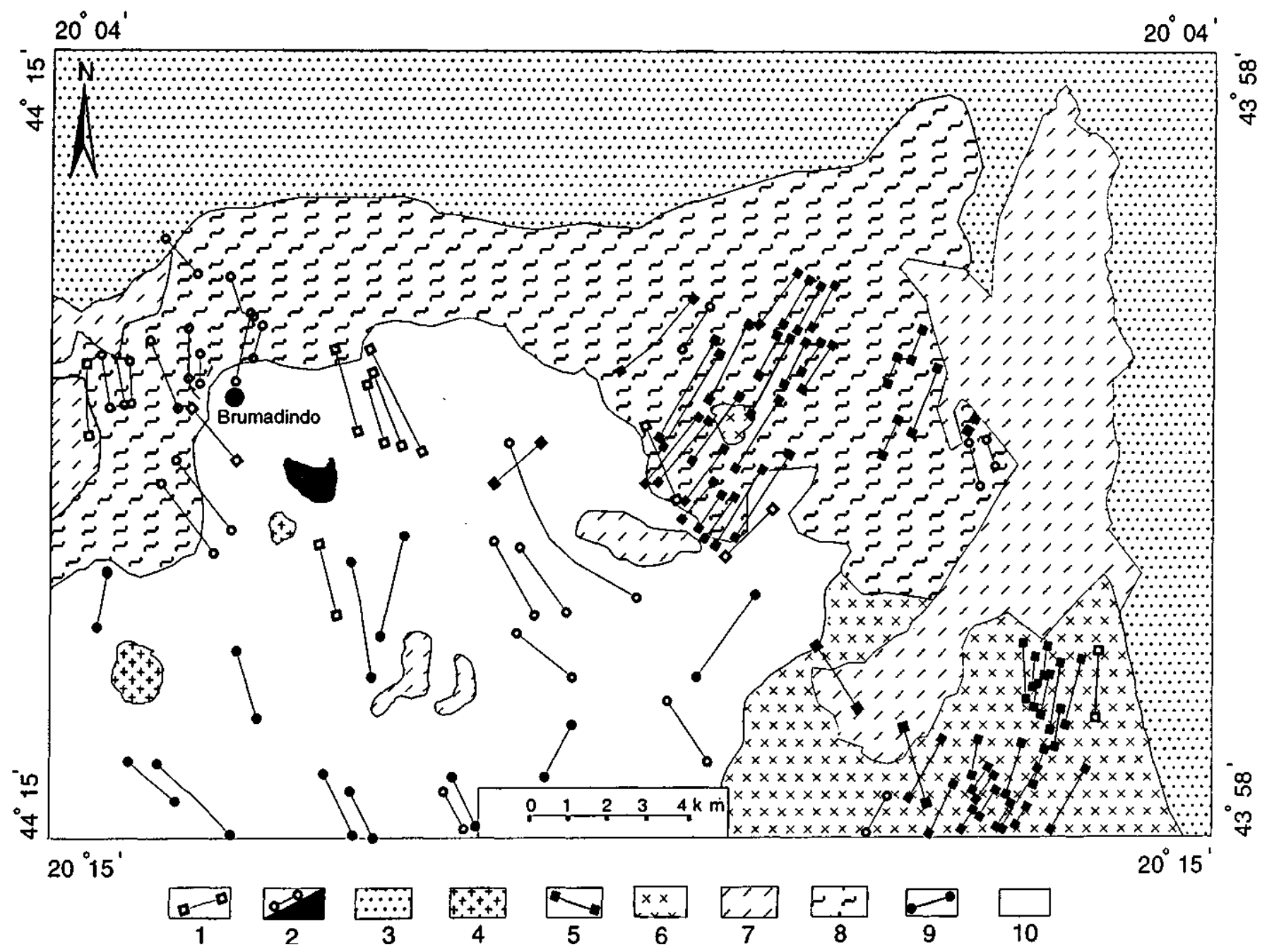

Figura 2 - Mapa geológico do Complexo Metamóifico Bonfim e de parte das sequências supracrustais do Quadrilátero Ferrífero (modificado de Carneiro et al 1997). Símbolos: 1 - Diabásio Santa Cruz; 2 - Metadiabásio Conceição do Itaguá; 3 - Super grupo Minas; 4 - Granito Brumadinho; 5 - Anfibolito Candeias; 6 - Tonalito Samambaia; 7 - Supergrupo Rio das Velhas; 8 - Gnaisse Souza Noschese; 9 - Anfibolito Paraopeba; 10 - Gnaisse Alberto Flores.

Figure 2 - Geologic map ofthe Bonfim Metamorpllic Complex andpart oftlie Quadrilátero Ferrifero sitpracrustal sequences (after Carneiro et al. 1997). Keys: l- Santa Cruz Diabase; 2 - Conceição de Itaguá Metadiabase; 3 - Minas Supergroup; 4 - Brumadinho Grani te; 5 - Candeias Ampliibolite; 6 - Samambaia Tonalite; 7 - Rio das Velhas Supergroup; 8 - Souza Noschese Gneiss; 9 - Paraopeba Amphibolite; W - Alberto Flores Gneiss.

camente intrudem o TS, o que caracteriza a presença, no CMBS, de dois eventos magmáticos arqueanos, um de natureza cálcio-alcalina e outro toleiítica (Carneiro et al. 1997). A intrusão das rochas da suite AC muito possivelmente remonta ao Arqueano, como sugere o valor levemente positivo do _ ${ }_{\mathrm{Nd}}(+0.1)$ modelado para $\mathrm{T}=2780 \mathrm{Ma}($ Tabela 2$)$.

$\overline{\mathrm{As}}$ rochas da suíte AC são melanocráticas, densas, faneríticas, eqüigranulares a ineqüigranulares médias, apresentando localmente fenoblastos de plagioclásio. Petrograficamente, estes anfibolitos diferem dos da primeira geração de diques. As diferenças mais imediatas residem nas características mesoscópicas gerais (fenoblastos de plagioclásio) e/ou microscópicas (hornblenda poiquiloblástica). Ademais, o seu modo de ocorrência e associação de campo também são distintos, pois afloram como diques bem preservados, de largura variada, predominantemente injetados nos TS e GSN (Cameiro 1992; Figura 2).

A textura das rochas da suite AC é granonematoblástica, caracterizada pela alternância de leitos de hornblenda e plagioclásio em cristais geralmente poligonizados e com junções tríplices. A hornblenda é poiquiloblástica, exibindo inúmeras inclusões anédricas de plagioclásio e quartzo. O plagioclásio, por sua vez, raramente ocorre em fenoblastos, os quais estão, em geral, intensamente saussuritizados. A hornblenda esverdeada é o principal constituinte destes anfibolitos e exibe, de maneira geral, um aspecto multigranular anédrico. Outras vezes, está recristalizada e pontilhada por inúmeras inclusões anédricas de plagioclásio ou, muito raramente, quartzo. Transformações secundárias para biotita castanha, clorita ou epídoto, são comuns nas amostras mais cisalhadas.

Biotita, clorita, sericita, epídoto e zoisita são secundários. A biotita é comumente castanha, desenvolve-se a partir da hornblenda e, associada a ela, ocorre clorita. Um acessório comum é a apatita. A titanita ocorre em finos agregados sugerindo tratar-se de leucoxênio, produto de alteração de titanomagnetita. A paragênese mineral de baixo grau destes anfibolitos está representada pela associação biotita + mica branca (sericita) + (epídoto e clinozoizita) + clorita.

A idade K-Ar obtida a partir de concentrados de hornblenda, é de $1707 \pm 64$ Ma (Tabela 3), idade está certamente influenciada pe!a paragênese de baixo grau desta suite que seria responsável por uma idade aparente pouco mais jovem que o padrão de rejuvenescimento $\mathrm{K}-\mathrm{Ar}$ das rochas da suite AP. 
Tabela 2 - Resultados geocronológicos Sm-Nd (rocha total) dos Anfibolitos Paraopeba e Candeias. Table 2 - Whole rock Sm-Nd geochronological data ofthe Candeias and Paraopeba Amphibolife.

\begin{tabular}{|c|c|c|c|c|c|c|c|c|c|c|c|}
\hline Sufle & Amostra & No Lah. & ${ }^{x+1} \sin -{ }^{x} \mathrm{Nu}$ & $\cdots \mathrm{Nu} \cdot{ }_{\mathrm{N}} \mathrm{Nu}$ & $\Gamma_{\text {smmit }}$ & $\operatorname{Sm}(\Gamma \mathrm{m})$ & Nd (ppm) & $\mathrm{T}_{\mathrm{Du}}(\mathrm{Mu})$ & $E_{x a}(1)$ & Ext $07 m_{0}$ & $\varepsilon_{\mathrm{*}: \mathrm{A}}(0)$ \\
\hline$\overline{\mathrm{AC}}$ & 301 & 198 & $0.1604 \pm 0,0002$ & $0.512027 \pm 0,(000023$ & $-(1), 18$ & 4,99 & 18.94 & 2960 & +1.74 & $+0,58$ & $-11,92$ \\
\hline $\mathbf{A P}$ & 120 & 142 & $0,1650 \pm 0,00012$ & $0,512071 \pm 0,0 \times 00038$ & -0.164 & 4.27 & 15,74 & 3120 & $+1,55$ & $-0,15$ & $-11,06$ \\
\hline
\end{tabular}

Idades TDM recalculadas conforme os parâmetros de DePaolo (1981). $\varepsilon_{\mathrm{Nd}}$ refere-se ao tempo inicial do cvcnlo Rio das Velhas (ver texto para detalhes).

Tabela 3-Resultados geocronológicos $\mathrm{K}$-Ar em hornblenda das quatro gerações de diques máficos do Complexo Metamórfico Bonfim Setentrional.

Table 3 - Hornblende K-Ar geochronological data ofthe Northern Bonfim Metamorphic Complex niafic dykes.

\begin{tabular}{|c|c|c|c|c|c|}
\hline Amostra & $\mathbf{N}^{0}$ Lab. & $K(\%)$ & $\begin{array}{c}{ }^{\mathrm{d0}} \mathrm{Ar} \text { atin. } \\
\%\end{array}$ & $\begin{array}{c}{ }^{40} r_{r a s}\left(\times 10^{-6}\right) \\
(\operatorname{ccSTP/g})\end{array}$ & $\begin{array}{c}\text { ldade } \\
\text { Aparente } \\
\text { (Ma) } \\
\end{array}$ \\
\hline \multicolumn{6}{|c|}{ Anfibolito Parnopeba } \\
\hline $\begin{array}{c}\text { AK7 } \\
\text { BN2 } \\
\text { CL7 } \\
\text { CN5/I } \\
\text { EK9 } \\
\text { FN1 }\end{array}$ & $\begin{array}{l}6729 \\
6733 \\
6731 \\
6732 \\
6727 \\
6728\end{array}$ & $\begin{array}{l}0,4783 \\
0,5128 \\
0,5165 \\
0,6998 \\
0,5887 \\
0,4612\end{array}$ & $\begin{array}{c}7,81 \\
10,68 \\
8,64 \\
6,43 \\
6,77 \\
7.88\end{array}$ & $\begin{array}{l}77,11 \\
74,16 \\
77,65 \\
97.09 \\
79,03 \\
65,12\end{array}$ & $\begin{array}{l}2157 \pm 80 \\
2022 \pm 72 \\
2067 \pm 34 \\
1972 \pm 73 \\
1930 \pm 31 \\
1991 \pm 46\end{array}$ \\
\hline \multicolumn{6}{|c|}{ Anfibolito Candeias } \\
\hline MM6/B & 6734 & 0,3240 & 12,27 & 35,74 & $1707 \pm 64$ \\
\hline \multicolumn{6}{|c|}{ Metadiabásio Conceição de Itaguá } \\
\hline KLII & 6730 & 0,4131 & 39.80 & 21,59 & $1006 \pm 43$ \\
\hline
\end{tabular}

Metadiabásio Conceição de Itaguá A terceira geração de diques máficos do CMBS é constituída por uma suite de rochas denominada de Metadiabásio Conceição de Itaguá (MCI). Estes diques são intrusivos no Supergrupo Minas, como se observa na porção NW da figura 2, o que permite atribuir-lhes uma idade posterior ao Paleoproterozóico. A idade mínima deste magmatismo foi obtida a partir de concentrados de hornblenda, a qual forneceu, pelo método K-Ar, um valor de $1006 \pm 43 \mathrm{Ma}$ (Tabela 3).

Os diques da suite MCI possuem largura variada c se orientam preferencialmente segundo NNW, subordinadamente NNE. Pequenos plutonitos e/ou bossas podem ser encontrados no CMBS (Fig. 2). No geral, são rochas sempre muito alteradas e devem corresponder aos "Anfibolitos Diabasóides" de Guimarães (1933).

Petrografícamente, as rochas desta suite do CMBS foram ígneas ligeiramente recristalizadas por mctamorfismo, como indica a presença de agregados de tremolita, epídoto, titanita, biotita castanha, estilpnomelana e opacos, desenvolvidos sobre minerais magmáticos representados por plagioclásio, piroxênio, hornblenda, K-feldspato e raro quartzo. Isto permite classificá-las como rochas ortometamórficas de baixo a médio grau.

A textura destas rochas é tipicamente ofítica, onde ripas de plagioclásio interceptam os cristais de piroxênio, com hornblenda intersticial. O plagioclásio é o principal constituinte destas rochas, seguido de tremolita, hornblenda e biotita. Em alguns casos, a saussuritização é intensa, quando, então, o plagioclásio está transformado em uma massa fina de epídoto e sericita. A hornblenda é castanha clara ou verde acastanhada e é primária e ocorre em cristais subédricos, mais raramente anédricos, intersticiais. A tremolita é verde ou verde acastanhada e é o segundo componente em volume. Este O mineral ocorre em cristais anédricos, mais raramente subédricos, crescidos às custas do piroxênio e/ou da hornblenda primária. Sobre estes dois minerais desenvolve-se a biotita lamelar castanha e/ou a clorita esverdeada. A biotita castanha e a

estilpnomelana amarelo dourado são muito frequentes. Esta última tem o aspecto de um agregado fibrorradiado ou plumoso, associada ao anfibólio e ao epídoto nos pseudomorfos de piroxênio. Na matriz, aparece na forma de lamelas. O quartzo é muito raro, pequeno, anédrico e intersticial. Localmente, pode ocorrer ortoclásio em pequenos cristais anédricos intersticiais com geminação tartan. A apatita é um acessório muito frequente e mostra prismas aciculares inclusos no plagioclásio. Os minerais opacos são muito frequentes, anédricos, às vezes corroídos e/ou esqueletiformes e possuem bordas de titanita anédrica, a qual, por sua vez, é muito frequente e pode estar associada à biotita ou à hornblenda, ou disseminada pela matriz feldspática.

Os minerais reliquiares de cristalização magmática destes diques compreendem plagioclásio $\pm \mathrm{K}$-feldspato \pm quartzo \pm hornblenda. Sobre esta associação desenvolveu-se uma paragênese metamórfíca com tremolita \pm estilpnomelana \pm biotita \pm clorita \pm saussurita. Portanto, a idade de $1006 \pm 43$ Ma, obtida em concentrado de anfibólio (Tabela 3), deve ser tomada forçosamente como a idade mínima de intrusão destes diques. A uralitização dos piroxênios para tremolita em baixo grau metamórfico pode estar relacionada ao soerguimento da crosta siálica do CSFM, ocorrida entre o final do Mesoproterozóico e o início do Neoproterozóico, evento esse que precedeu a instalação e evolução da bacia sedimentar do "São Francisco". Por outro lado, cabe notai- que diques máficos com idade ${ }^{40} \mathrm{Ar} /{ }^{39} \mathrm{Ar}$ plateau de $1975 \pm 7 \mathrm{Ma}$, obtida a partir de anfibólio, foram recentemente reportados por Pinese (1997). Estes diques são petrográfica e composicionalmente semelhantes aos da suite MCI e também são intrusivos no Supergrupo Minas na serra de Bom Sucesso, a sudoeste da área em estudo). Isto corrobora a hipótese de que idade de colocação da terceira geração de rochas máficas do CMBS está associada à orogenia Transamazônica.

Diabásio Santa Cruz A geração mais jovem de diques máficos do CMBS foi denominada por Carneiro (1992) de Diabásio Santa Cruz (DSC). Os diques desta geração têm orientação NNW, com raras ocorrências NNE. Suas rochas ainda não foram objeto de datações radiométricas, mas a sua natureza subvulcânica, evidenciada por suas texturas, permitem considerá-las como de colocação subsuperficial e, portanto, relativamente recente na evolução crustal do CMBS.

As rochas desta geração são melanocráticas, afaníticas a faneríticas, eqüigranulares finas e afloram de duas maneiras. Uma como enxames de diques de largura centimétrica de diabásios afaníticos pretos esverdeados, geralmente muito intemperizados. Outra, consiste de diques mais espessos, decimétricos, de rochas afaníticas a faneríticas finas, pretas a pretas esverdeadas. A sua textura é predominantemente intergranular e/ou blasto-intergranular, caracterizada por cristais ripiformes de plagioclásio, com clinopiroxênio e opacos intersticiais. Variações para textura ofitica (e/ou blasto-ofítica) com plagioclásio ripiforme incluso em clinopiroxênio também ocorrem nestas rochas.

Localmente, o clinopiroxênio tem uma textura coronítica e foi substituído, das bordas para o centro, por uma mistura de anfibólio esverdeado e, mais raramente, por biotita castanha. O plagioclásio é o principal constituinte em volume destas rochas e ocorre em cristais subédricos, mais raramente euédricos, zonados e geminados segundo as leis Carlsbad e da 
Albita. Apesar do aspecto geralmente límpido, o plagioclásio pode mostrar inclusões de anfibólio, biotita e epídoto. Raramente o plagioclásio está amplamente saussuritizado. $\mathrm{O}$ clinopiroxênio (augita) é o segundo componente em volume destas rochas e é, em geral, anédrico, mais raramente subédrico e está sistematicamente substituído por anfibólio e/ou biotita. $\mathrm{O}$ anfibólio é verde azulado a verde acastanhado, anédrico, raramente subédrico, e comumente ocorre nas bordas do piroxênio recristalizado. As características óticas deste anfibólio apontam para uma ferro-actinolita. A biotita é castanha, em franjas, e está frequentemente situada nas bordas de minerais opacos. Outras vezes associa-se ao anfibólio, desenvolvendo-se às custas do piroxênio. Cristais isolados de biotita também podem ser observados na matriz feldspática. $\mathrm{O}$ quartzo é raro, anédrico, intersticial ou inclusões nos cristais de feldspato. O ortoclásio é raro nestas rochas, e, quando presente, é anédrico, intersticial, tem geminação tartan e mostra intercrescimento com quartzo vermicular. Os opacos são anédricos, corroídos, com aspecto esqueletiforme e/ou simplectítico. Além de franjas de biotita, os opacos também podem apresentar titanita granular anédrica nas bordas. Apatita e titanita são acessórios comuns, mas em quantidade muito subordinada, principalmente a última. Epídoto, clorita e sericita são secundários a partir de plagioclásio, hornblenda ou biotita.

LITOGEOQUIMICA Do conjunto de amostras, das quatro gerações de diques máficos do $\mathrm{CMBS}$, as mais representativas foram selecionadas para um estudo geoquímico de rocha total. Os resultados analíticos constam da Tabela 4. Visando avaliar a extensão da mobilidade de elementos maiores durante processos secundários, realizou-se uma série de testes gráficos, dentre os quais destaca-se o de Beswick \& Soucie (1978), gerado a partir de dados analíticos de rochas vulcânicas pós-mesozóicas não alteradas. Estes autores advogam que o uso das razões da proporção molecular (MPR) dos principais óxidos (e.g. $\mathrm{SiO}_{2}, \mathrm{Al}_{2} \mathrm{O}_{3}, \mathrm{FeO}, \mathrm{MnO}, \mathrm{MgO}$, $\mathrm{CaO}, \mathrm{Na}_{2} \mathrm{O}$ e $\mathrm{K}_{2} \mathrm{O}$ ), definem um envelope de correlação com o qual amostras quaisquer podem ser confrontadas para verificar a presença e intensidade de mobilização dos elementos maiores em processos posteriores (metamorfismo, alteração, etc.).

A figura 3 mostra a distribuição das amostras das quatro gerações de diques máficos do CMBS em relação ao envelope

Tabela 4 - Composição química de amostras selecionadas das quatro gerações de diques máficos do Complexo Metamórfico Bonfim Setentrional.

Table 4 - Chemical composition of selected samples of the Northern Bonfim Metamorphic Complex mafic dykes.

\begin{tabular}{|c|c|c|c|c|c|c|c|c|c|c|c|c|c|c|c|c|c|}
\hline \multicolumn{9}{|c|}{ Anfibolito Paraopeba } & \multicolumn{9}{|c|}{ Anfibolito Candeias** } \\
\hline & AJ7 & $\mathrm{BN2}$ & CL7 & CN5-2 & EK9 & EK 10 & FNI & 1512 & HK4-A & JGI-C & JG4:A & JG4-L & JHS-A & KH3-A & KH3-L & LJ10 & MLB-C \\
\hline $\mathrm{SiO}_{2}$ & 51,20 & 49,10 & 49,20 & 49,10 & 50,50 & 50,90 & 48,60 & 49,30 & 50,10 & 49,00 & 50,10 & 49,40 & 50,60 & 51,30 & 49,60 & 49,20 & 51,20 \\
\hline $\mathrm{TiO}_{2}$ & 1,60 & 1,80 & 1,80 & 1,80 & 1,50 & 1,50 & 1,00 & 2,60 & 2,60 & 1,60 & 1,90 & 2,10 & 1,60 & 2,00 & 1,70 & 1,90 & 1,20 \\
\hline $\mathrm{Al}_{2} \mathrm{O}_{3}$ & 14,30 & 14,40 & 14,90 & 14,30 & 14,50 & 15,10 & 15,80 & 12,50 & 15.80 & 13,60 & 13,10 & 12,60 & 14,20 & 13,10 & 12,90 & 13,20 & 14,00 \\
\hline $\mathrm{Fe}_{2} \mathrm{O}_{3}$ & 1,70 & 2,70 & 1,80 & 2,10 & 1,50 & 1,30 & 1,80 & 2,20 & 3,60 & 2,90 & 3,20 & 2,10 & 1,30 & 1,50 & 2,60 & 1,20 & 1,80 \\
\hline $\mathrm{FeO}$ & 10,90 & 10,40 & 10,20 & 10,30 & 10,70 & 10,70 & 8,30 & 14,10 & 8,70 & 10,40 & 11,50 & 12,90 & 12,00 & 13,60 & 13,10 & 12,90 & 11,10 \\
\hline $\mathrm{MnO}$ & 0.19 & 0,21 & 0.20 & 0,20 & 0.21 & 0,21 & 0.18 & 0,25 & 0.19 & 0,21 & 0.23 & 0.23 & 0.19 & 0.22 & 0.25 & 0,22 & 0,19 \\
\hline $\mathrm{MgO}$ & 5,00 & 6,00 & 6,10 & 6,20 & 5,60 & 4,70 & 7,80 & 4,90 & 3,10 & 6,40 & 5,60 & 5,60 & 5,60 & 4,30 & 5,10 & 6,00 & 5,90 \\
\hline $\mathrm{CaO}$ & 10,20 & 9,70 & 10,10 & 9,50 & 10,40 & 10,20 & 10,50 & 9,60 & 9,20 & 10.70 & 10.30 & 10,70 & 10,80 & 9,90 & 10,20 & 10,60 & 11,10 \\
\hline $\mathrm{Na}_{2} \mathrm{O}$ & 2,00 & 2,50 & 2,60 & 2,70 & 2,40 & 2,50 & 2,60 & 2,60 & 4,10 & 2,30 & 2.50 & 2,50 & 2,00 & 2,40 & 2,70 & 2,50 & 2,10 \\
\hline $\mathrm{K}_{2} \mathrm{O}$ & 0,71 & 1,10 & 1,00 & 1,80 & 0.84 & 0,94 & 1.70 & 0,40 & 0.28 & 0,54 & 0,49 & 0,49 & 0,45 & 0,45 & 0,49 & 0,36 & 0.28 \\
\hline $\mathrm{P}_{2} \mathrm{O}_{5}$ & 0,15 & 0,22 & 0.19 & 0,19 & 0.13 & 0,14 & 0.11 & 0,27 & 0.38 & 0,16 & 0,28 & 0.21 & 0,16 & 0,19 & 0,19 & 0,21 & 0,10 \\
\hline $\mathrm{BaO}$ & 0,02 & 0,01 & 0,02 & 0,03 & 0,01 & 0,02 & 0,02 & $<0,01$ & $<0,01$ & $<0,01$ & $<0,01$ & $<0,01$ & $<0,01$ & 0,01 & 0,01 & $<0,01$ & $<0,01$ \\
\hline$S$ & 0,13 & 0,10 & 0,07 & 0,13 & 0,12 & 0,13 & 0,08 & 0,16 & 0,14 & 0,10 & 0,10 & 0,11 & 0.11 & 0,11 & 0,13 & 0,13 & 0,09 \\
\hline $\mathbf{F}$ & 0,04 & 0,03 & 0,04 & 0,03 & 0,03 & 0,03 & 0,08 & 0,04 & 0,03 & 0,02 & 0,03 & 0,03 & 0.02 & 0,03 & 0,03 & 0,03 & 0,02 \\
\hline $\mathrm{CO}_{2}$ & 0,34 & 0,34 & 0,34 & 0,34 & 0,26 & 0,26 & 0,26 & 0,34 & 0,34 & 0,34 & 0,34 & 0,26 & 0,34 & 0,34 & 0,26 & 0,34 & 0,34 \\
\hline $\mathrm{H}_{2} \mathrm{O}+$ & 1,40 & 1,38 & 1.38 & 1,38 & 1.31 & 1,43 & 1,15 & 0,68 & 1.48 & 1,63 & 0,24 & 0,80 & 0,69 & 0,61 & 0,56 & 1,08 & 0,59 \\
\hline S.Tot & 99,88 & 99,99 & 99.94 & 100,10 & 100,01 & 100,06 & 99,98 & 99,94 & 100,04 & 99,90 & 99,91 & 100,03 & 100,06 & 100,06 & 99,82 & 99,87 & 100,01 \\
\hline $\mathrm{O}=\mathrm{F}$ & 0,02 & 0,01 & 0,02 & 0,01 & 0,01 & 0.01 & 0,03 & 0,02 & 0,01 & $<0,01$ & 0,01 & 0,01 & $<0,01$ & 0,01 & 0,01 & 0,01 & $<0,01$ \\
\hline S.Fin & 99,86 & 99,98 & 99,92 & 100,09 & 100,00 & 100,05 & 99,95 & 99,92 & 100,03 & 99,90 & 99,90 & 100,02 & 100,06 & 100,05 & 99,81 & 99,86 & $100,0 !$ \\
\hline $\mathrm{H}_{2} \mathrm{O}-$ & 0,07 & 0,07 & 0,08 & 0,06 & 0,03 & 0,03 & 0,08 & 0,04 & 0,06 & 0,07 & 0,03 & 0,03 & 0,06 & 0,06 & 0,03 & 0,03 & 0,04 \\
\hline $\mathrm{Cr}^{*}$ & 148 & 122 & 158 & 120 & 162 & 136 & 340 & 128 & 62 & 200 & 120 & 220 & 220 & 132 & 136 & 230 & 340 \\
\hline $\mathrm{Ni}^{*}$ & 108 & 118 & 166 & 106 & 112 & 94 & 180 & 126 & 78 & 100 & 86 & 142 & 146 & 102 & 112 & 156 & 158 \\
\hline Co & 50 & 49 & 54 & 46 & 50 & 51 & 45 & 51 & 64 & 44 & 43 & 58 & 52 & 66 & 58 & 60 & 84 \\
\hline$V$ & 298 & 338 & 348 & 308 & 348 & 278 & 258 & 308 & 308 & 288 & 228 & 458 & 228 & 288 & 438 & 468 & 268 \\
\hline $\mathrm{Cu}$ & 50 & 47 & 34 & 81 & 63 & 69 & 16 & 103 & 63 & 103 & 75 & 66 & 100 & 94 & 81 & 113 & 88 \\
\hline $\mathrm{Zn}$ & 143 & 133 & 130 & 140 & 133 & 133 & 100 & 197 & 143 & 147 & 187 & 167 & 127 & 137 & 137 & 137 & 113 \\
\hline $\mathbf{R b}$ & 26 & 38 & 37 & 73 & 23 & 24 & 81 & $<10$ & $<10$ & 24 & $<10$ & $<10$ & 10 & 17 & 15 & 10 & $<10$ \\
\hline $\mathrm{Ba}$ & 140 & 120 & 160 & 230 & 130 & 150 & 130 & 41 & 20 & 72 & 84 & 74 & 75 & 96 & 110 & 67 & 24 \\
\hline Sr & 130 & 170 & 150 & 180 & 120 & 120 & 170 & 91 & 480 & 110 & 100 & 88 & 110 & 100 & 97 & 94 & 120 \\
\hline $\mathrm{Nb}$ & 33 & 42 & 42 & 28 & 44 & 36 & 24 & 42 & 32 & $<20$ & 20 & 52 & $<20$ & $<20$ & 36 & 58 & $<20$ \\
\hline $\mathrm{Zr}$ & 176 & 178 & 178 & 160 & 162 & 148 & 98 & 230 & 260 & 134 & 172 & 240 & 156 & 210 & 182 & 210 & 132 \\
\hline $\mathrm{Y}$ & 66 & 70 & 69 & 59 & 70 & 67 & 48 & 84 & 100 & 56 & 77 & 104 & 64 & 86 & 74 & 82 & 70 \\
\hline $\mathrm{Cl}$ & 230 & 790 & 670 & 590 & 230 & 200 & $<20$ & 480 & 150 & 180 & 280 & 310 & 130 & 170 & 200 & 190 & $<20$ \\
\hline La & 11,49 & - & 11,25 & - & - & 11,66 & . & - & . & 7,84 & - & 13,75 & 9,82 & - & - & - & - \\
\hline $\mathrm{Ce}$ & 31,78 & - & 38,43 & - & - & 30,79 & - & - & - & 29,20 & - & 41,54 & 29,26 & - & - & - & - \\
\hline Nd & 18,74 & - & 18,36 & - & - & 16,67 & - & - & - & 14,64 & - & 23,17 & 16,59 & - & - & - & . \\
\hline $\mathrm{Sm}$ & 4,92 & - & 4,88 & - & - & 4,44 & - & - & - & $4,[I$ & - & 6,87 & 4,72 & $=$ & - & . & - \\
\hline $\mathrm{Eu}$ & 1,39 & = & 1,30 & - & . & 1,30 & - & - & - & 1,14 & - & 1,67 & 1,22 & $=$ & - & - & - \\
\hline Gd & 4,09 & - & 3,49 & - & - & 3,70 & - & - & - & 3,22 & - & 5,58 & 3.87 & - & - & - & - \\
\hline Dy & 5,98 & - & 4,69 & - & . & 5,31 & - & - & - & 4,45 & - & 7,37 & 5,40 & $=$ & = & - & . \\
\hline $\mathrm{Ho}_{\mathrm{o}}$ & 1,25 & - & 0,97 & - & - & 1,00 & - & - & - & 0,93 & - & 1,50 & 1,13 & - & - & - & - \\
\hline Er & 3,62 & - & 2,98 & - & - & 3,21 & - & - & - & 2,83 & - & 4,55 & 3,34 & - & - & - & - \\
\hline $\mathrm{Yb}$ & 3,37 & - & 2,65 & . & $=$ & 2,97 & - & . & - & 2,45 & - & 4,04 & 2,89 & - & $=$ & - & $=$ \\
\hline Lu & 0,38 & - & 0,35 & - & - & 0,35 & - & - & - & 0,29 & - & 0,50 & 0,36 & - & - & - & - \\
\hline
\end{tabular}

Teores calculados a partir de $\mathrm{Cr}_{2} \mathrm{O}_{3}$ e NiO.: **Dados de Carneiro et al. (1997) 
de não alteração definido por Beswick \& Soucie (1978). A figura revela que as razões entre elementos maiores não foram modificadas de modo significativo por mobilidade dos elementos, apesar do metamorfismo e, em alguns casos, de uma longa residência crustal. Portanto, podem ser utilizadas em estudos petrogenéticos voltados à investigação de sua origem e dos respectivos ambientes tectônicos. Entretanto, na medida do possível, serão evitadas considerações petrogenéticas que envolvam os óxidos ou suas razões.

Classificação Química Inúmeras têm sido as propostas para classificação química de rochas ígneas. A grande maioria (e.g. Irvine \& Baragar 1971, Cox et al. 1979, De La Roche et al. 1980, Lê Bas et al. 1986) leva em consideração, somente, alguns elementos maiores ( $\mathrm{Si}, \mathrm{Na}, \mathrm{K} \mathrm{e} \mathrm{Mg}$ ).

Segundo os critérios de Irvine \& Baragar (1971) (Fig. 4), as quatro gerações de diques máficos do CMBS são de natureza toleiítica. Contudo, estes critérios são, em princípio, contra-indicados para classificar orto-anfibolitos, em vista da mobilidade dos elementos considerados nestes diagramas de classificação durante processos secundários.
Por conseguinte, os elementos de menor mobilidade química durante o metamorfismo, como $\mathrm{Nb}, \mathrm{Y}, \mathrm{Zr}$ e Ti), são mais adequados para estudos petrogenéticos de rochas metamórficas, como proposto por Winchester \& Floyd (1977).

Razões que empregam $\mathrm{Nb}, \mathrm{Y}, \mathrm{Zr}$ e Ti têm implicações petrogenéticas, como a razão $\mathrm{Nb} / \mathrm{Y}$, que constitui um indicador seguro de alcalinidade dos magmas (Pearce \& Cann 1973, Floyd \& Winchester 1975, Winchester \& Floyd 1977). A razão $\mathrm{Zr} / \mathrm{TiC}_{2}$, por outro lado, ao aumentar com a diferenciação progressiva de um magma básico, reflete o declínio geral do conteúdo de $\mathrm{TiC}_{2}$ nos diferenciados não basálticos (Winchester \& Floyd 1977) e, por isto, pode ser usada como um sensível índice de diferenciação no lugar de $\mathrm{SiC} » 2$. Estas razões, portanto, substituem com muita propriedade, outras, tais como a razão sílica/álcalis, cujos elementos são mais susceptíveis à mobilidade em processos secundários.

A figura 5 mostra a distribuição das amostras das quatro gerações de diques máficos do CMBS no diagrama de Winchester \& Floyd (1977). As quatro gerações distribuem-se em três domínios principais. Destaca-se, em primeiro lugar, uma nítida separação entre as amostras das suites AP e AC. As da

\begin{tabular}{|c|c|c|c|c|c|c|c|c|c|c|c|c|c|c|c|}
\hline \multicolumn{10}{|c|}{ Metadiabásio Conceição de Itaguá } & \multicolumn{6}{|c|}{ Diabásio Santa Cruz } \\
\hline & BII-15 & BJ4-1 & $\mathrm{CJ} 2$ & DJ7 & FN3 & $\mathrm{IH7}$ & IH7-L & KLl I & NJ7 & A12-A & $\mathrm{Cl} 2$ & IJ 13 & IK8 & MK6 & NL18 \\
\hline $\mathrm{SiO}_{2}$ & 52,50 & 56,20 & 52,70 & 49,00 & 53.70 & 49,00 & 49,10 & 51,10 & 48,90 & 48,20 & 48,70 & 53,20 & 53,30 & 48,00 & 46,40 \\
\hline $\mathrm{TiO}_{2}$ & 2,90 & 2,50 & 2,60 & 1,90 & 2,20 & 3,40 & 3,30 & 2,40 & 3,60 & 3,20 & 3,10 & 2,40 & 2,40 & 3,30 & 2,10 \\
\hline $\mathrm{Al}_{2} \mathrm{O}_{3}$ & 14,20 & 13,70 & 13,60 & 16,90 & 15,90 & 12,50 & 12,90 & 14,30 & 14,20 & 12,80 & 12,60 & 13,80 & 13,00 & 13,10 & 17,40 \\
\hline $\mathrm{Fe}_{2} \mathrm{O}_{3}$ & 1,50 & 5,90 & 7,60 & 1,90 & 2,00 & 2,90 & 3,00 & 2,20 & 3,00 & 2,30 & 3,20 & 1,70 & 1,20 & 2,60 & 2,80 \\
\hline $\mathrm{FeO}$ & 10,40 & 5,80 & 5,10 & 9,10 & 8,00 & 11,20 & 10,90 & 10,70 & 10,60 & 11,70 & 10,40 & 12,30 & 12,30 & 12,80 & 10,30 \\
\hline $\mathrm{MnO}$ & 0,18 & 0,18 & 0,20 & 0,19 & 0,23 & 0,26 & 0,25 & 0,27 & 0,21 & 0,25 & 0,25 & 0,19 & 0,20 & 0,26 & 0,21 \\
\hline $\mathrm{MgO}$ & 2.70 & 2,10 & 2,40 & 4,70 & 2.50 & 4,10 & 3,80 & 2,80 & 3,20 & 5,60 & 5,60 & 3,40 & 3,30 & 5,50 & 6,00 \\
\hline $\mathrm{CaO}$ & 6,80 & 5,00 & 6,70 & 10,00 & 5,30 & 8,50 & 8,60 & 7,10 & 9,40 & 9,70 & 10,30 & 7,40 & 7,30 & 9,70 & 11,00 \\
\hline $\mathrm{Na}_{2} \mathrm{O}$ & 3,40 & 3,80 & 4,50 & 2,80 & 5,50 & 3.50 & 3,90 & 5,40 & 3,30 & 1,30 & 1,30 & 2,60 & 3,30 & 2,40 & 1,50 \\
\hline $\mathrm{K}_{2} \mathrm{O}$ & 2,90 & 1,90 & 1,60 & 0,89 & 1,40 & 0,80 & 0,80 & 0,58 & 0,84 & 0.31 & 0,76 & 1,90 & 2,20 & 0,69 & 0,50 \\
\hline $\mathrm{P}_{2} \mathrm{O}_{5}$ & 0,61 & 0,61 & 0,62 & 0,19 & 0,81 & 0,71 & 0,75 & 0,99 & 0,87 & 0,39 & 0,40 & 0,32 & $0,3 !$ & 0,58 & 0,22 \\
\hline $\mathrm{BaO}$ & 0,10 & 0,06 & 0,18 & 0,03 & 0,08 & 0,04 & 0,05 & 0,08 & 0,05 & $<0.01$ & $<0.01$ & 0,07 & 0,07 & 0,04 & 0,06 \\
\hline$S$ & 0,11 & 0,02 & 0,05 & 0,09 & 0,02 & 0,12 & 0,16 & 0,22 & 0,07 & 0,30 & 0,13 & 0,11 & 0,13 & 0,05 & 0,24 \\
\hline $\mathbf{F}$ & 0.08 & 0,13 & 0,12 & 0,03 & 0,13 & 0,08 & 0.08 & 0,08 & 0,08 & 0,06 & 0,07 & 0,10 & 0,06 & 0,08 & 0,07 \\
\hline $\mathrm{CO}_{2}$ & 0,34 & 0,34 & 0,26 & 0,26 & 0,26 & 0,34 & 0,26 & 0,34 & 0,34 & 0,43 & 0,34 & 0,20 & 0,43 & 0,20 & 0,20 \\
\hline $\mathrm{H}_{2} \mathrm{O}^{+}$ & 1,27 & 1,70 & 1,75 & 2,02 & 1,99 & 2,55 & 2,12 & 1.44 & 1,13 & 3,31 & 2,93 & 0,30 & 0,39 & 0,54 & 0,83 \\
\hline S.Tot & 99,99 & 99,94 & 99,98 & 100,00 & 100,02 & 100,00 & 99,97 & 100,00 & 99,79 & 99.85 & 100,08 & 100,01 & 99,89 & 99,86 & 99,86 \\
\hline $\mathrm{O}=\mathrm{F}$ & 0,03 & 0,05 & 0,05 & 0,01 & 0,05 & 0,03 & 0,03 & 0,03 & 0,03 & 0,03 & 0,03 & 0,04 & 0,03 & 0,03 & 0,03 \\
\hline S.Fin & 99,96 & 99,89 & 99,93 & 99.99 & 99,97 & 99.97 & 99,94 & 99,97 & 99,76 & 99,82 & 100,05 & 99.97 & 99,86 & 99,83 & 99,83 \\
\hline $\mathrm{H}_{2} \mathrm{O}^{-}$ & 0,05 & 0,13 & 0,38 & 0,04 & 0,05 & 0,16 & 0,16 & 0,05 & 0,03 & 0,07 & 0,05 & 0,08 & 0,04 & 0,09 & 0,08 \\
\hline $\mathrm{Cr}$ & 50 & 15 & 15 & 192 & 40 & 11 & 18 & 37 & 61 & 124 & 144 & $20^{*}$ & 82 & $48^{*}$ & $44^{*}$ \\
\hline $\mathrm{Ni}$ & 40 & 36 & 46 & 72 & 32 & 39 & 42 & 40 & 77 & 106 & 122 & $47 *$ & 77 & $119 *$ & $86 *$ \\
\hline Co & 41 & 40 & 35 & 44 & 29 & 39 & 54 & 41 & 45 & 56 & 56 & 55 & 82 & 54 & 53 \\
\hline V & 188 & 258 & 208 & 182 & 168 & 248 & 288 & 172 & 338 & 338 & 428 & 290 & 358 & 460 & 360 \\
\hline $\mathrm{Cu}$ & 34 & 25 & 25 & 38 & 13 & 38 & 28 & 41 & 94 & 113 & 122 & 62 & 63 & 70 & 77 \\
\hline $\mathrm{Zn}$ & 167 & 167 & 170 & 120 & 217 & 167 & 165 & 160 & 66 & 157 & 167 & 154 & 177 & 172 & 117 \\
\hline $\mathrm{Rb}$ & 82 & 75 & 74 & 31 & 33 & 30 & 27 & 11 & 11 & 34 & 69 & 37 & 42 & 10 & $<10$ \\
\hline $\mathrm{Ba}$ & 890 & 530 & 1570 & 270 & 740 & 340 & 430 & 740 & 460 & 27 & 32 & $655^{*}$ & 600 & $313^{*}$ & $573^{*}$ \\
\hline $\mathrm{Sr}$ & 360 & 260 & 290 & 350 & 400 & 240 & 240 & 360 & 650 & 260 & 230 & 160 & 220 & 330 & 140 \\
\hline $\mathrm{Nb}$ & 40 & 82 & 74 & 36 & 80 & 70 & 88 & 88 & 64 & 52 & 68 & $<20$ & 68 & $<20$ & $<20$ \\
\hline $\mathrm{Zr}$ & 340 & 440 & 400 & 188 & 440 & 320 & 350 & 520 & 240 & 250 & 290 & 350 & 320 & 260 & 200 \\
\hline $\mathrm{Y}$ & 71 & 75 & 84 & 56 & 61 & 64 & 74 & 69 & 70 & 69 & 83 & 55 & 78 & 55 & 43 \\
\hline $\mathrm{Cl}$ & 97 & 180 & 160 & 65 & 140 & 140 & 140 & 78 & 1470 & $<20$ & $<20$ & 120 & 130 & 600 & 36 \\
\hline La & - & 61,96 & $=$ & $=$ & - & 41,73 & + & - & 21,84 & $=$ & - & - & - & - & - \\
\hline $\mathrm{Ce}$ & $=$ & 141,30 & $=$ &. & - & 100,60 & . & - & 66,09 & . & - & - & - & - & - \\
\hline $\mathrm{Nd}$ & - & 74,41 & - & - & - & 58,83 & - & - & 40,71 & - & - & - & $=$ & $=$ & $=$ \\
\hline $\mathrm{Sm}$ & - & 15,37 & - & - & - & 12,52 & - & - & 9,64 & - & - & - & $=$ & $=$ & . \\
\hline$E_{u}$ & - & 3,93 & . & - & - & 3,54 &. & . & 3,34 & . & . & - & - & - & - \\
\hline Gd & - & 8,42 & - & - & - & 7,35 & - & - & 6,18 & - & - & - & - & - & - \\
\hline Dy & $=$ & 7,96 & . & - & . & 7,18 & . & . & 5,98 & $=$ & $=$ & - & - & $=$ & - \\
\hline Ho & - & 1,50 & - & - & - & 1,38 & - & - & 1,14 & - & - & - & . & - & - \\
\hline $\mathrm{Er}$ & - & 4,04 & - & . & . & 3,47 &. & . & 2,97 &. & . & - & - & $=$ & . \\
\hline $\mathrm{Yb}$ & - & 3,08 & - & - & - & 2,79 & - & - & 2,24 & - & - & - & - & - & - \\
\hline Lu & - & 0,36 & - & - & - & 0,29 & - & - & 0,24 & - & - & - & - & - & - \\
\hline
\end{tabular}



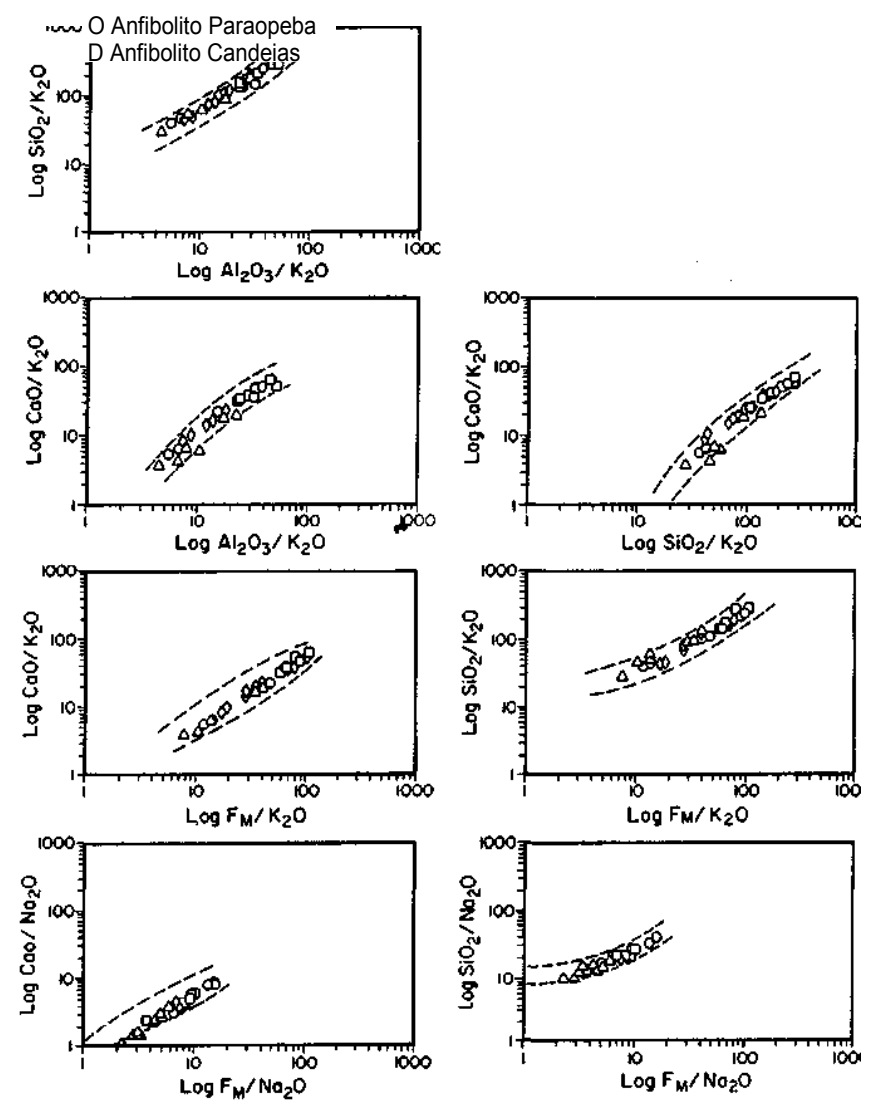

A Metadiabásio Conceição de Itaguá o Diabásio Santa Cruz

Figura 3 - Diagramas das razões de proporção molecular (MPR) das quatro gerações de diques máficos do Complexo Metamórfico Bonfim Setentrional.

Figure 3 - MPR diagrams of the Northern Bonfim Metamorphic Complex mafic dykes.

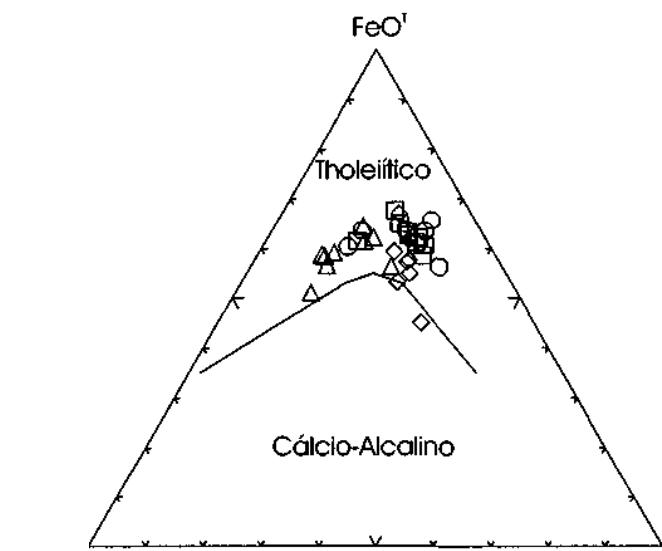

$\mathrm{Na}_{2} \mathrm{O}+\mathrm{K}_{2} \mathrm{O}$

$\mathrm{MgO}$

$\checkmark$ Anfibolito Paraopeba $\Delta$ Metadiabásio Conceição de Itaguá $\square$ Anfibolito Candeias O Diabásio Santa Cruz

Figura 4 - Classificação geral das quatro gerações de diques máficos do Complexo Metamórfico Bonfim Setentrional de acordo com o diagrama AFM, segundo a proposta de Irvine \& Baragar (1971).

Figure 4 - Chemical classification of the Northern Bonfim Metamorphic Complex mafic dykes in the AFM diagram (after Irvine \& Baragar 1971).

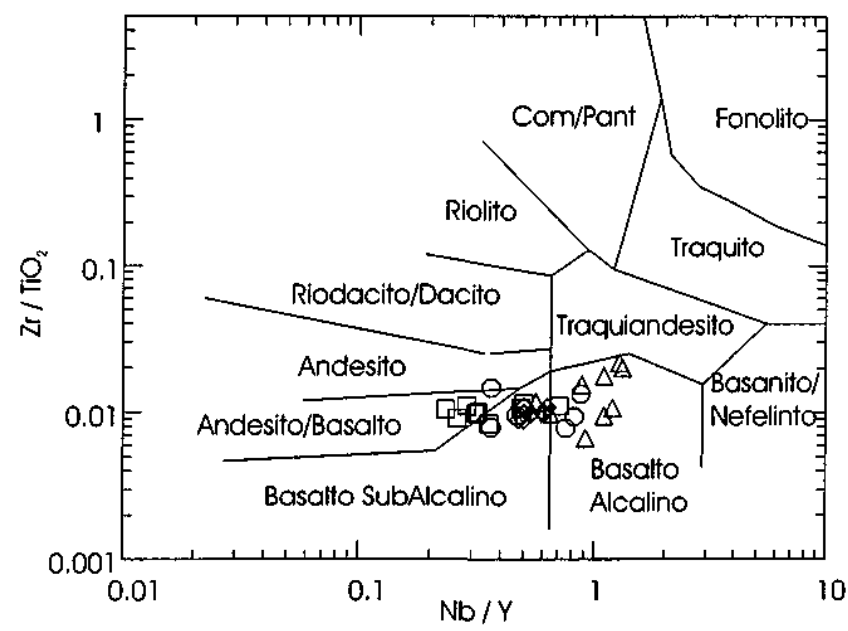

$\checkmark$ Anfibolito Paraopeba $\Delta$ Metadiabásio Conceição de Itaguá $\square$ Anfibolito Candeias 0 Diabásio Santa Cruz

Figura 5 - Classificação geral das quatro gerações de diques máficos do Complexo Metamórfico Bonfim Setentrional segundo a proposta de Winchester \& Floyd (1977).

Figure 5 - Chemical classifications of the Northern Bonfim Metamorphic Complex mafic dykes in the $\mathrm{Nb} / \mathrm{Y}$ against $\mathrm{Zr} / \mathrm{TiO} \mathrm{O}_{2}$ (after Winchester \& Floyd 1977).

suite AP tem uma reduzida variação da razão $\mathrm{Nb} / \mathrm{Y}$, o que as concentra no limite entre os campos dos basaltos sub-alcalinos e andesitos. As da suite AC, por seu turno, apresentam razões $\mathrm{Nb} / \mathrm{Y}$ predominantemente menores que as da AP, concentrando-se no limite do campo dos andesitos, com variações para o campo dos basaltos alcalinos. O carater mais "alcalino" de amostras da suite AP, que contrasta com o mais "andesítico" das da suite $\mathbf{A C}$, é comum em rochas máficas anfibolitizadas que passaram por eventos de retrabalhamento crustal (Floyd \& Winchester 1978) e está de acordo com situação geológica de ambas suítes.

As rochas da suite AP, submetidas a metamorfismo mais acentuado, apresentam uma composição mais primitiva e estão relacionadas à unidade litoestratigráfica mais antiga do CMBS (GAF). Como as rochas da suite GAF sofreram pelo menos dois eventos metamórficos (Carneiro 1992), o carater mais básico e/ou alcalino da suite AP (Fig. 5) poderia decor-

Tabela 5 - Razões médias de alguns elementos de potencial iônico intermediário das quatro gerações de diques máficos do Complexo Metamórfico Bonfim Setentrional. Al-Anfibolito Paraopeba; A.I - Anfibolito Candeias; AI-Metadiabásio Conceição de Itaguá; A4 - Diabásio Santa Cruz.

Table 5 -Average ratios of the intermediary ionic potential elements of Northern Bonfim Metamorphic Complex mafic dykes. Ai - Paraopeba Amphibolite; A2 - Candeias Amphibolite; AÍ - Conceição de Itaguá Metadiabase; A4 - Santa Cruz Diabase.

\begin{tabular}{|cccccccccc|}
\hline & $\mathrm{Al}_{2} \mathrm{O}_{3}$ & $\mathrm{P}_{2} \mathrm{O}_{5}$ & $\mathrm{TiO}_{2}$ & $\mathrm{~V}$ & $\mathrm{Co}$ & $\mathrm{Y}$ & $\mathrm{Zr}$ & $\mathrm{Nb}$ & $\mathrm{Ce}$ \\
\hline $\mathrm{A}_{1} / \mathrm{A}_{2}$ & 1,06 & 0,81 & 0,92 & 0,93 & 0,83 & 0,84 & 0,88 & $>1,16$ & 1,01 \\
$\mathrm{~A}_{1} / \mathrm{A}_{3}$ & 1,01 & 0,25 & 0,61 & 1,36 & 1,19 & 0,97 & 0,46 & 0,52 & 0,37 \\
$\mathrm{~A}_{1} / \mathrm{A}_{4}$ & 1,05 & 0,46 & 0,62 & 0,83 & 0,87 & 1,22 & 0,59 & $>0,87$ & - \\
$\mathrm{A}_{2} / \mathrm{A}_{3}$ & 0,95 & 0,31 & 0,67 & 1,44 & 1,44 & 1,14 & 0,52 & $<0,45$ & 0,32 \\
$\mathrm{~A}_{2} / \mathrm{A}_{4}$ & 0,99 & 0,57 & 0,67 & 0,89 & 1,05 & 1,43 & 0,67 & $>0,75$ & - \\
$\mathrm{A}_{3} / \mathrm{A}_{4}$ & 1,03 & 1,83 & 1,00 & 0,61 & 0,73 & 1,25 & 1,29 & $>1,68$ & - \\
\hline
\end{tabular}



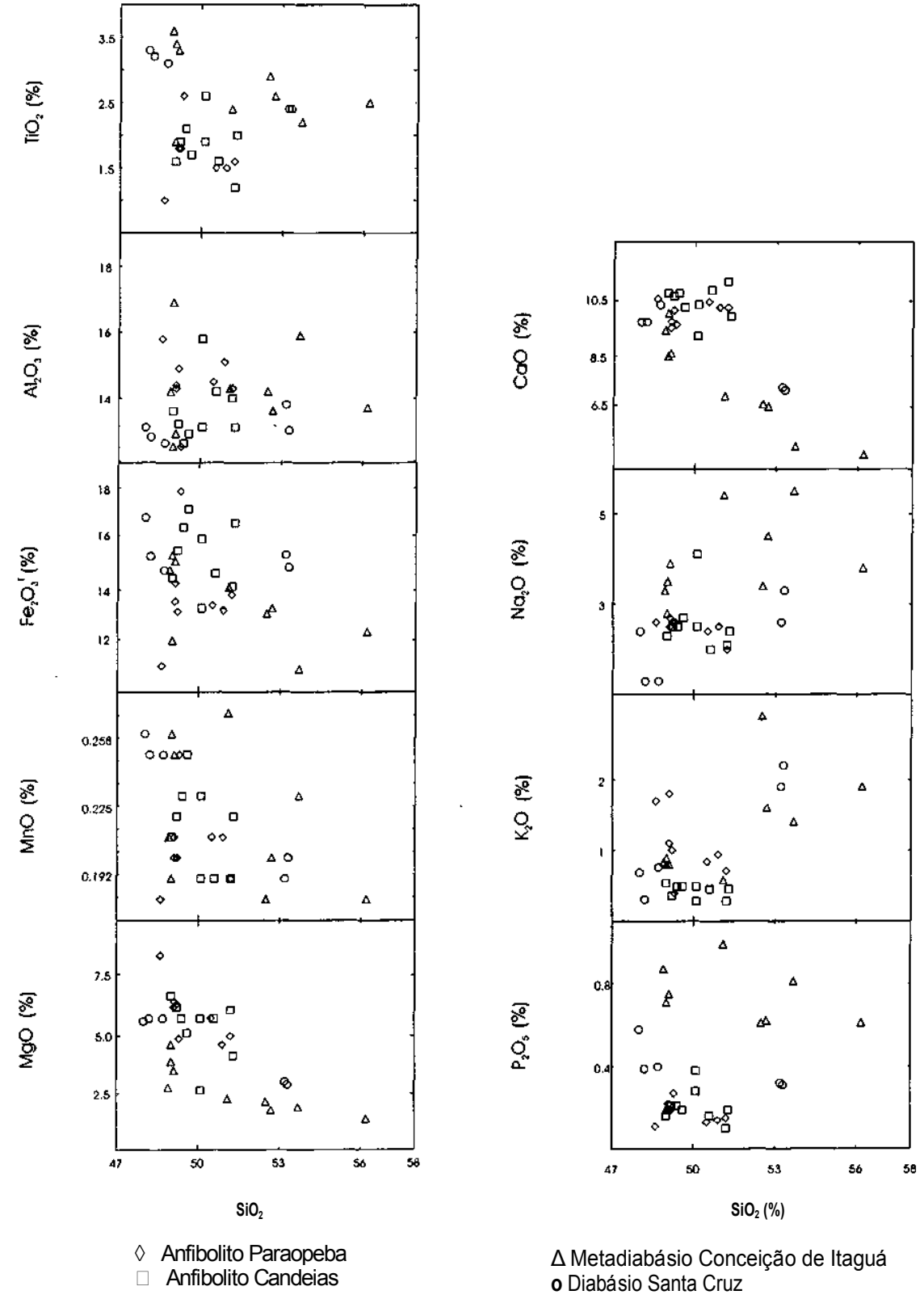

Figura 6 - Diagramas de variação ( $\mathrm{SiO}_{2}$ versus Óxidos) para as quatro gerações de diques máficos do Complexo Metamórfico Bonfim Setentrional.

Figure 6 - Selected diagrams ( $\mathrm{SiO}_{2}$ plotted against Oxides) for the Northern Bonfim Metamorphic Complex mafic dykes.

rer, em parte, das transformações metamórficas, mas também refletir uma fonte mantélica mais primitiva.

Já as rochas da suite AC possuem características metamórficas mais brandas, composição mais andesítica e estão associadas a um plutonismo cálcio-alcalino (diques no TS). Tais características e suas maiores proporções em elementos imóveis, comparativamente às rochas da suite $\mathbf{A P}$, sugerem que a composição atual das amostras da suite $\mathbf{A C}$ não deve diferir muito da dos seus protólitos. A julgar pelas evidências isotópicas de $\mathrm{Nd}$ e pêlos dados de campo, as diferenças entre ambas podem ser atribuídas pulsos magmáticos distintos. $\mathrm{O}$ primeiro foi responsável pela colocação dos protólitos da suite AP, com idade mínima de 2920 Ma, posteriormente metamorfizados há $2780 \mathrm{Ma}$ (Carneiro 1992, Machado \& Carneiro 1992). O segundo, responsável pela injeção dos magmas que geraram os protólitos da suite $\mathbf{A C}$, logo após o magmatismo cálcio-alcalino da suíte TS, acorrido há $2780 \mathrm{Ma}$ (Carneiro 1992, Machado \& Carneiro 1992, Carneiro et al. 1997).
As rochas da suite $\mathbf{M C I}$, por sua vez, estão distribuídas em dois subdomínios bem característicos e de padrões bastante diferenciados. É particularmente notável a tendência mais extensa que evolui de basaltos sub-alcalinos e/ou andesitos até traquiandesíticos bastante diferenciados (Fig. 5). O segundo subdomínio, situado no campo dos basaltos alcalinos, indica, como no primeiro, um fonte mais rica em $\mathrm{Zr}$ e Nb, em detrimento $\mathrm{TiO}_{2}$ e Y.

As rochas da suite DSC dividem-se entre os campos das rochas subalcalinas e alcalinas. No primeiro caso, não se observa qualquer tendência e as três amostras podem ser classificadas como andesitos. No segundo, as amostras restantes apresentam uma tendência bem marcada através dos campos dos álcali-basaltos e traquiandesitos. É interessante notar que um conjunto de diques máficos composicionalmente similares aos da suite DSC foi caracterizado na região de Lavras e para os quais Pinese (1997) infere uma idade Mesozóica. 

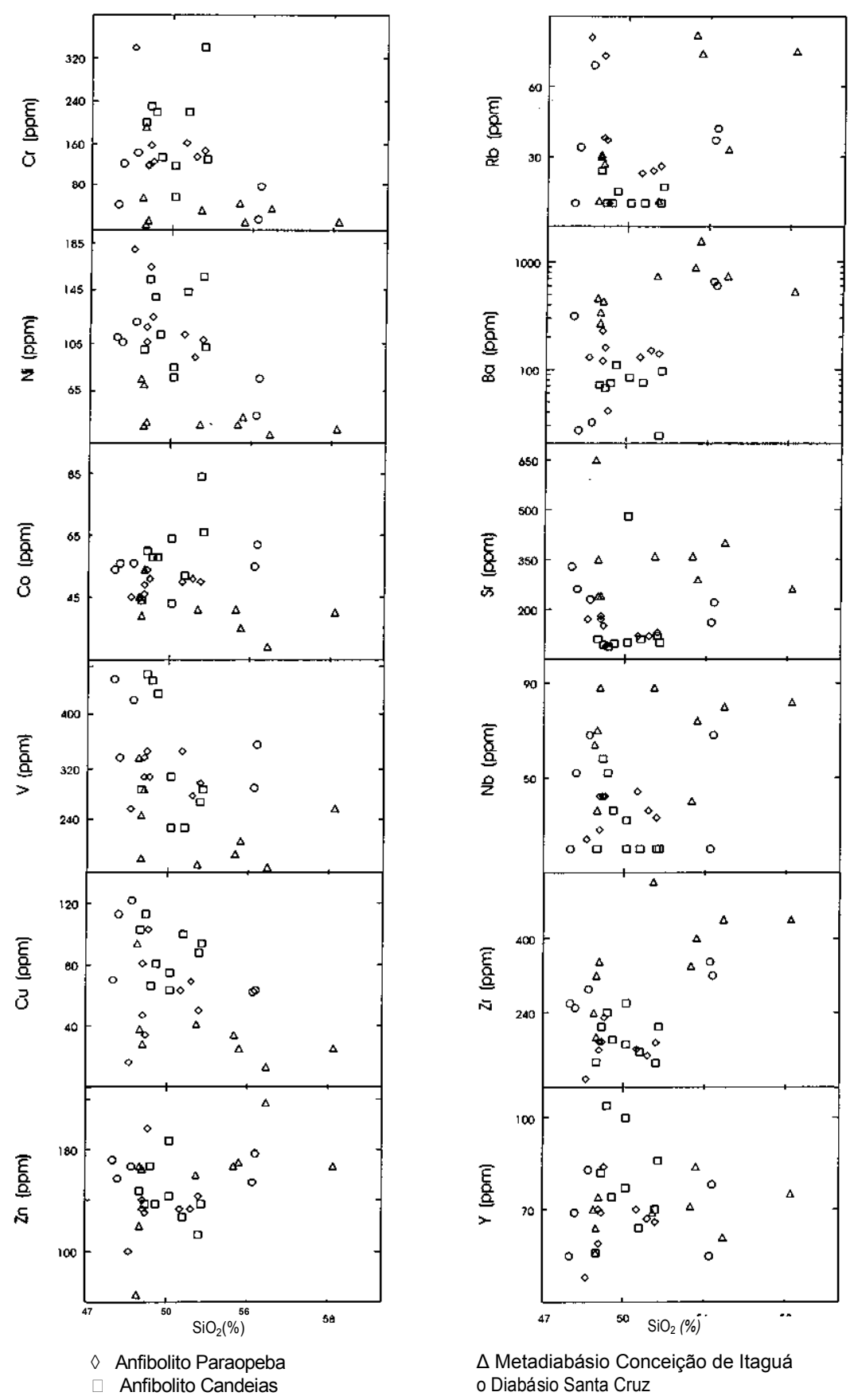

Figura 7 - Diagramas de variação (SiO2 versus Elementos Traços) para as quatro gerações de diques máficos do Complexo Metamórfico Bonfim Setentrional.

Figure 7 - Selected diagrams (SiOiplotted against trace elements) for the Northern Bonfim Metamorphic Complex mafic dykes.

Composição Química Total A composição química de rocha total das suites AP e AC mostra, variavelmente, semelhanças e diferenças entre si. As diferenças mais expressivas residem nos teores mais elevados de $\mathrm{Al}_{2} \mathrm{O}_{3}, \mathrm{~K}_{2} \mathrm{O}, \mathrm{Rb}$ e $\mathrm{Ba}$ nas rochas da suite $\mathrm{AP}$ e $\mathrm{Fe}_{2} \mathrm{O}_{3}$ (total) $\mathrm{Cu}$ e $\mathrm{Y}$ nas da suite AC (Figs. 6 e 7).

Considerando as quatro gerações de diques, as diferenças mais acentuadas ocorrem entre as mais metamorfizadas (AP e AC) e as com metamorfismo de menor grau (MCI e DSC). É marcante, por exemplo, o elevado conteúdo de TiÜ2 das suites, MCI e DCS (Fig. 6), em contraste com o das suites AP e AC. O contraste entre as suites mais e menos metamorfizadas se repete na maioria dos diagramas das figuras 6 e 7. As rochas da suite MCI caracterizam-se, sistematicamente, por teores mais elevados em $\mathrm{TiOz}, \mathrm{Na}_{2} \mathrm{O}, \mathrm{P}_{2} \mathrm{O}_{5}, \mathrm{Ba}, \mathrm{Sr}, \mathrm{Nb}$ e $\mathrm{Zr}$ e, ao mesmo tempo, teores expressivamente mais baixos de $\mathrm{MgO}$, $\mathrm{CaO}, \mathrm{Cr}, \mathrm{Ni}, \mathrm{Co}, \mathrm{V}$ e $\mathrm{Cu}$. Além disto, o seu teor médio de $\mathrm{P}_{2} \mathrm{O}_{5}, \mathrm{TiO}_{2}, \mathrm{Zr}$, Nb e Ce é sempre mais elevado que nas demais gerações.

As amostras da suíte DSC, muito embora não apresentem uma distribuição homogénea e sistemática como as da suite MCI, têm um padrão semelhante ao desta. Estes diabásios são moderadamente ricos em $\mathrm{TiO}_{2}, \mathrm{P}_{2} \mathrm{O}_{5}, \mathrm{~V}, \mathrm{Cu}, \mathrm{Rb}, \mathrm{Ba}, \mathrm{Zr}$ e pobres em Ni e Sr. Por outro lado, as amostras da suite MCI apresentam teores moderados de $\mathrm{P}_{2} \mathrm{O}_{5}, \mathrm{TiO}_{2}, \mathrm{~V}, \mathrm{Zr}$ e Nb , mas maiores que as da suites $\mathrm{AP}$ e $\mathrm{AC}$, e são mais ricas em $\mathrm{V}$ e Co que as da suite MCI. 

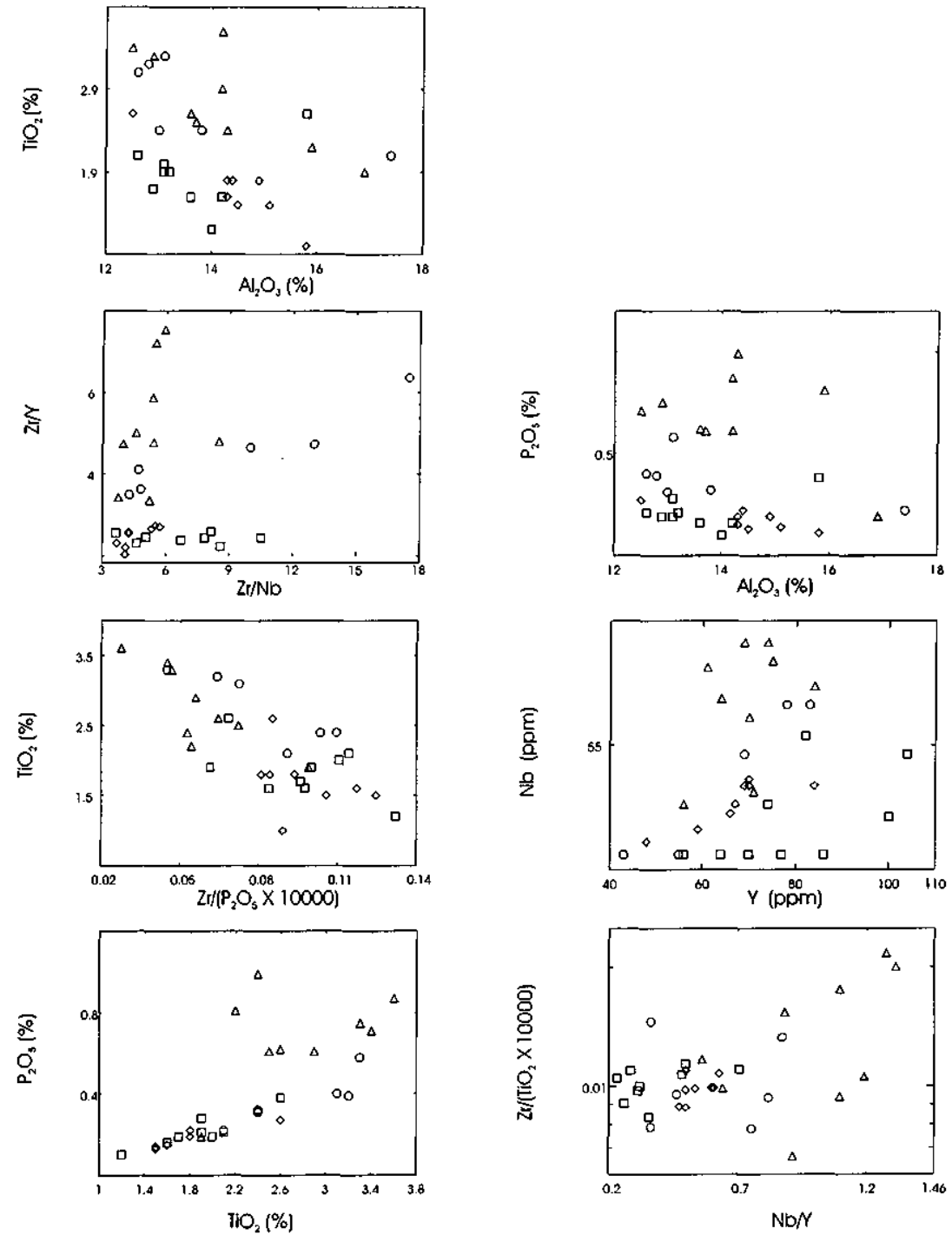

$\diamond$ Anfibolito Paraopeba $\square$ Anfibolito Candeias

$\triangle$ Méadiabósio Conceição de Itaguá O Diabásio Santa Cruz

Figura 8 - Diagramas de variação para alguns elementos e/ou razões de elementos de potencial iônico intermediário das quatro gerações de diques máficos do Complexo Metamórfico Bonfim Setentrional.

Figure 8 - Selected element ratio diagrams ofthe Northern Bonfim Metamorphic Complex mafic dykes.

Além destas diferenças gerais, os elementos imóveis e/ou incompatíveis das quatro gerações de diques também apresentam algumas particularidades químicas mais sutis. Para efeitos comparativos, a Tabela 5 apresenta algumas razões calculadas a partir do teor médio de $\mathrm{Al}_{2} \mathrm{O}_{3}, \mathrm{P}_{2} \mathrm{O}_{5}, \mathrm{TiC}_{2}, \mathrm{~V}, \mathrm{Co}, \mathrm{Y}, \mathrm{Zr}, \mathrm{Nb}$ e Ce. As rochas da suite AP são mais ricas em $\mathrm{Al}$ que as demais e são mais ricas em $\mathrm{Nb}$ e Ce que as da suíte $\mathbf{A C}$, em $\mathrm{Al}, \mathrm{V}$ e Co que as da suite MCI e em Y que as da suite DSC. Nos demais elementos, as outras gerações são, sistematicamente, mais ricas.

A figura 8 , apresenta diagramas construídos a partir de alguns elementos da Tabela 5. Há uma notável separação entre as quatro gerações de diques máficos estudadas, que reflete a sua mineralogia e o seu estágio evolutivo. Sistematicamente, as rochas da suites $\mathbf{A P}$ e $\mathbf{A C}$ são mais pobres em $\mathrm{TiO}_{2}, \mathrm{P}_{2} \mathrm{O}_{5}$, $\mathrm{Nb}$ e na razão $\mathrm{Zr} / \mathrm{Nb}$. Já as da suíte MCI são mais ricas em TiOz, P2Ü5, Nb e na razão $\mathrm{Zr} / \mathrm{Y}$. As da suite DCS exibem, em geral, um comportamento geoquímico intermediário entre as suites mais anfibolíticas (AP e AC), mas ostentam, além de um amplo e regular espalhamento de razões no diagrama $\mathrm{Zr} / \mathrm{Nb}$ x $\mathrm{Zr} / \mathrm{Y}$, os valores mais elevados da razão $\mathrm{Zr} / \mathrm{Nb}$. Ainda conforme a figura 8 , as diferenças mais significativas entre as rochas da suites AP e AC ocorrem nos diagramas AhOs $x$ $\mathrm{TiC}_{2}, \mathrm{Al}_{2} \mathrm{O}_{3} \times \mathrm{P}_{2} \mathrm{O}_{5}, \mathrm{Zr} / \mathrm{Nb} \times \mathrm{Zr} / \mathrm{Y} \times \mathrm{Zr} /(\mathrm{TiU} 2 \mathrm{U}$ x 10000) e $\mathrm{Y}$ $\mathrm{x} \mathrm{Nb}$. Nestes diagramas, a suite AP é sempre mais rica em AhOs ou em $\mathrm{Nb}$. Já a suíte $\mathbf{A C}$ é sempre mais rica em Y e a sua razão $\mathrm{Zr} / \mathrm{Nb}$ é, substancialmente, mais elevada que a da suite AP. Entre as suites MCI e DSC, as principais diferenças ocorrem nos diagramas $\mathrm{Al}_{2} \mathrm{O}_{3}$ x $\mathrm{P}_{2} \mathrm{O}_{5}, \mathrm{Y}$ x Nb e $\mathrm{TiO}_{2}$ x $\mathrm{P}_{2} \mathrm{O}_{5}$. Sistematicamente, a suite MCI mostra tendências mais amplas e mais ricas em $\mathrm{P}_{2} \mathrm{O}_{5}$ e Nb. A suíte DSC está bem marcada nos diagramas $\mathrm{Zr} / \mathrm{Nb}$ x $\mathrm{Zr} / \mathrm{Y}$ e $\mathrm{Zr} /\left(\mathrm{P}_{2} \mathrm{O}_{5} \mathrm{X}\right.$ 10.000) x $\mathrm{TiO}_{2}$. Assim, os diagramas mostram claramente que as quatro gerações de diques máficos do CMBS possuem características geoquímicas particulares e, em muitos casos, contrastantes entre si.

MAGMAS PARENTAIS E PROCESSOS DE CRISTALIZAÇÃO Em geral, o estudo geoquímico de rochas máficas e/ou anfibolitos do Arqueano e do Proterozóico, tem utilizado uma grande variedade de diagramas discriminantes 
(petrogenéticos, tectônicos, etc.), originalmente propostos para basaltos modernos. Contudo, rochas não necessariamente ígneas podem adquirir aspectos típicos de metabasaltos no decorrer dos processos secundários. Assim, é necessário descartar gerações e/ou amostras que possam ter sido lavas (ácidas, intermediárias ou ultrabásicas), tipos fracionados (ou cumulatos), plutonitos e, naturalmente, para-anfibolitos. Isto é uma tarefa difícil, pois a grande maioria dos anfibolitos pode apresentar irremediavelmente transformados na sua textura, mineralogia e composição química.

No presente estudo, várias precauções foram tomadas para evitar amostras de para-anfibolitos. Para isto, durante a amostragem procurou-se coletar somente rochas de diques, evitando ao máximo corpos alterados, cisalhados ou morfologicamente duvidosos. Como as gerações foram originalmente definidas a partir de um conjunto de critérios quanto ao modo de ocorrência, associação pctrográfica e textura, o seu quimismo, ao confirmar a separação tentativa, tornou-se um critério adicional para futuros trabalhos. Se os cuidados adotados permitem considerar que as gerações em discussão são ortoderivadas, os seus parâmetros químicos permitem investigar as identidades petrogenélicas originais dos protólitos e dos processos de cristalização magmática envolvidos.

A razão $\mathrm{Ti} / \mathrm{Zr}$ tem sido muito utilizada para testar o caráter magmático de uma suíte de rochas máficas (Winchester \& Floyd 1977, Stillman \& Williams 1979, Pearcc 1982, Pharaoh \& Pearce 1984, Watters \& Pearce 1987, Condie 1989, Condie 1990). As razões petrogenéticas da escolha desses elementos são bem conhecidas e seu comportamento é controlado pela cristalização fracionada de um magma básico. No início da cristalização magmática, quando as fases minerais dominantes são representadas por olivina, piroxênio e plagioclásio, a razão $\mathrm{Ti} / \mathrm{Zr}$ da fusão permanece praticamente inalterada. A partir do início da cristalização de fases minerais que fracionam $\mathrm{Ti}$, a razão $\mathrm{Ti} / \mathrm{Zr}$ decresce, rápida e simultaneamente, com o incremento de $\mathrm{SiO}_{2}$ no líquido. Esta passagem marca uma mudança significativa no caráter químico do magma que, até então, produzia rochas de composição mais básica. Com esta mudança, o líquido é capaz de produzir rochas mais diferenciadas. $\mathrm{O}$ valor exato da razão $\mathrm{TiO}_{2} / \mathrm{Zr}$ que delimita $\mathrm{o}$ campo entre as rochas primitivas e as evoluídas é controverso. Neste artigo adotamos a razão $\mathrm{Ti} / \mathrm{Zr}=42$, correspondente à razão $\mathrm{TiO}_{2} / \mathrm{Zr}=70$ de Stillman \& Williams (1979).

A figura 9 mostra a distribuição das quatro gerações de diques máficos estudados e que se enquadram no campo das rochas mais primitivas, as quais se caracterizam por dois domínios principais. Um é constituído pelas amostras das suites AP e AC, que definem uma tendência paralela à linha P-E. Outro é constituído pela quase todas as amostras das suites MCI e DSC, e descreve uma tendência transversal à linha P-E, em direção ao campo das rochas mais evoluídas.

Nos protólitos das rochas da suites AP e AC, a evolução do líquido a partir de uma fonte de baixa razão $\mathrm{Zr} / \mathrm{Ti}$ ocorreu por cristalização fracionada, onde nenhuma fase mineral rica em Ti ou Zr foi extraída do mesmo, o que é indicado por uma razão relativamente uniforme. Por outro lado, a formação dos protólitos da suite MCI ocorreu a partir de um magma oriundo de uma fonte consideravelmente rica em Ti e a extração de fases minerais tais como a magnetita, promoveu uma considerável redução da razão Ti/Zr. Assim, a composição básica original do líquido variou, paulatinamente, para os termos mais diferenciados, como indica a correlação negativa apresentada na figura 9 .

PADRÃO GEOQUíMICO E AMBIENTE TECTÔNICO O padrão geoquímico médio das quatro gerações de diques máficos do CMBS (Fig. 10) exibe, além de um forte enriquecimento em quase todos os elementos incompatíveis, comparativamente ao MORB típico, um nítido contraste entre

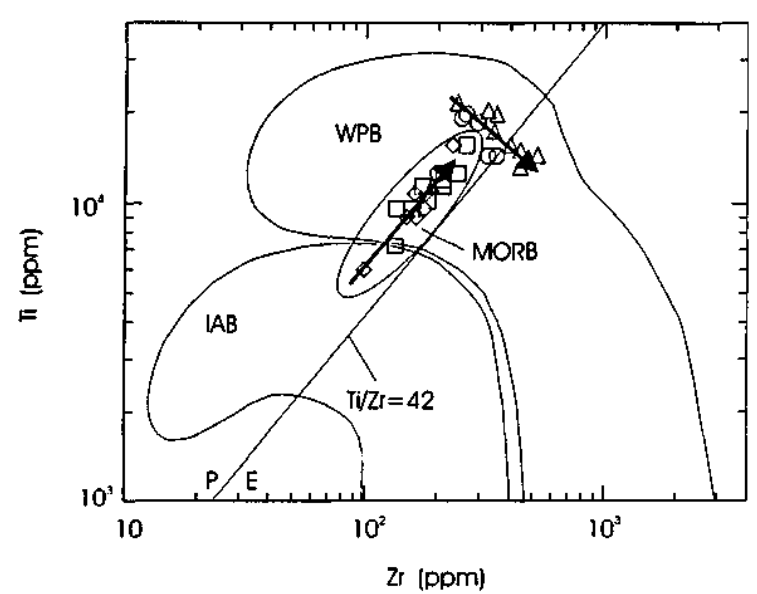

$\diamond$ Anfibolito Paraopeba

$\square$ Anfibolito Candeias

$\Delta$ Metadiabásio Conceição de Itaguá oDiabásio Santa Cruz

Figura 9 - Diagrama Zr versus Ti para as quatro gerações de diques máficos do Complexo Metamórfico Bonfim Setentrional. A linha diagonal (Ti/Zr=42) separa o campo das rochas primitivas à esquerda $(\boldsymbol{P})$ e evoluídas $(\boldsymbol{E})$ a direita. As linhas cheias delimitam os campos ocupados pêlos basaltos modernos do tipo MORB, IAB e WPB (Pharaoh \& Pearce 1984). As setas indicam as tendências evolutivas das gerações

em estudo.

Figure 9 - Plots of Zr againsl Ti for lhe Northern Bonfim Melamorphic Complex niafic dykes. The diagonal Une $(T i / Z r=42)$ liinits the fields ofthe primitive rocks at lefl $(\boldsymbol{P})$ and evolved rocks $(\boldsymbol{E})$ ai righl and lhe arrows indicale evolution Irends ofthe inafic dykes. MORB, IAB and WPB fields are fmin Pharaoh \& Pearce (1984).

os padrões das suites mais metamorfizadas (AP e AC) e as menos metamorfizadas (MCI e DSC). O padrão geoquímico das suites AP e AC apresenta anomalias negativas de $\mathrm{Ba}$ e P2Ü5 e positivas de Y e são discretamente mais ricas em $\mathrm{Cr}$ que as outras gerações. Além disto, estas suites são sistematicamente mais pobres em elementos incompatíveis do que as suítes MCI e DSC, exceto em Y e Cr. A suíte MCI é a mais rica $\mathrm{cm}$ elementos incompatíveis. $\mathrm{O}$ seu padrão geoquímico, e o da suite DSC, se caracteriza por um enriquecimento crescente e abrupto de $\mathrm{Sr}, \mathrm{K}, \mathrm{Rb}$ e $\mathrm{Ba}$, seguido por um empobrecimento relativamente suave até o $\mathrm{Cr}$.

Estes contrastes também ocorrem com os Elementos Terras Raras (ETR) (Fig. 11). A suite MCI exibe um padrão altamente fracionado e, sistematicamente, muito mais enriquecido em Terras Raras Leves do que as suites AP e AC. Estas, por sua vez, apresentam um padrão bem menos fracionado e são levemente mais ricas em Terras Raras Pesadas que a suite MCI. A suite AC, por sua vez, é levemente mais rica em ETR do que a suite AP, exceto em La.

A figura 12 mostra a distribuição dos valores médios das gerações de diques estudados em diagrama discriminante de ambientes geotectônicos e envelope de variação dos basaltos modernos intraplaca, adaptado de Pearce $(1982,1983)$ e Pharaoh \& Pearce (1984). As quatro gerações enquadram-se no intervalo de variação destes basaltos. Isto é muito evidente nas suítes MCI e DSC, cujos comportamentos são correlacionáveis aos dos basaltos alcalinos intraplaca, à semelhança dos que ocorrem nos Açores (e.g. Pearce 1982, 1983, Pharaoh \& Pearce 1984). Todavia, as suítes AP e AC, a despeito de sua semelhança com o padrão das suítes MCI e DSC e, consequentemente, com o dos basaltos intraplaca, ostenta algumas particularidades. Destaca-se, além das anomalias negativas de Ba e positivas de $\mathrm{Y}$, o seu empobre- 


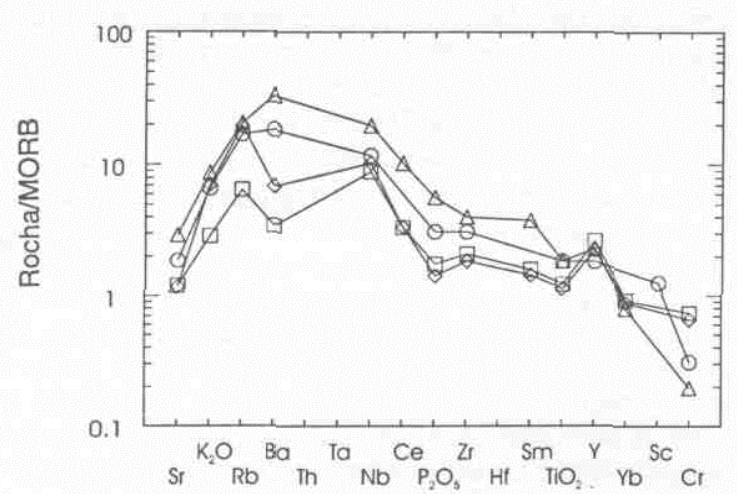

$\checkmark$ Anfibolito Paraopeba $\square$ Anfibolito Candeias

$\triangle$ Metadiabásio Conceição de Itaguá O Diabásio Santa Cruz

Figura 10 - Padrão geoquímico da composição média das quatro gerações de diques máficos do Complexo Metamórfico Bonfim Setentrional, normalizados pêlos valores de Pearce (1982, 1983).

Figure 10 - MORE iwrmalized elements and oxides paliem for lhe Norlliern Bonfim Metamorphic Complex mafic dykex (valuesfrom Pearce 1982, i983).

cimento regular em elementos incompatíveis, frente às sitites MCI e DSC.

Isto pode estar relacionado tanto a anomalias (s.l.) decorrentes de processos secundários (e.g. rcmobilização de $\mathrm{K}$ e $\mathrm{Rb}$ ), quanto a anomalias relacionadas à natureza da fonte mantélica (e.g. concentrações elevadas de $\mathrm{Ti}, \mathrm{Zr}$ e/ou Nb). Neste sentido, a passagem do Arqueano para o Prolerozóico tem sido considerada como um período de apreciáveis mudanças na composição do manto e da crosta continental (Pharaoh \& Pearce 1984, Taylor \& McLennan 1985, Condic $1985,1989)$. Nesse contexto, os basaltos c andcsitos, por sua derivação direta de fontes mantélicas, têm sido utilizados como marcadores dessa transição (Condie 1985, 1989, 1990, 1997, Condie et al. 1987). Assim, de acordo com Condic (1985, 1989) e Condie et al. (1987), os basaltos arqueanos diferenciam-se dos basaltos proterozóicos, dentre outros aspectos, por (1) seu conteúdo médio menos de $\mathrm{Sr}, \mathrm{K}, \mathrm{Rb}, \mathrm{Ba}$, Th, P, Zr, Hf, Ti, Y e ETRL, (2) seu padrão de ERT menos fracionado, (3) razões Ti/Zr menores e (4) por seu conteúdo mais elevado de $\mathrm{Cr}$ e Ni. Todas estas características estão presentes e discriminam, perfeitamente, as snites arqueanas (AP e AC) das do Proterozóico (MCI) do CMBS. Comparativamente, as rochas da suítes AP e AC são sistematicamente mais pobres em $\mathrm{Sr}, \mathrm{K}, \mathrm{Rb}, \mathrm{Ba}, \mathrm{P}, \mathrm{Zr}$ e Ti e mais ricas em $\mathrm{Cr}$ e Ni que as das suites MCI e DSC (Tabela 4).

Por outro lado, as suites mais metamorfizadas (AP c AC) têm um padrão menos fracionado em ETRL do que a suíte MCI (Fig. 11). A distinção está bem destacada na figura 13 pêlos padrões geoquímicos médios dos diques estudados, exceto os da suite DSC, não analisados, comparativamente com alguns envelopes de variação dos ETR de basaltos arqueanos e fanerozóicos (Condie 1981). Destaca-se na figura 13, em primeiro lugar, um nítido contraste de fracionamento dos ETRL mais acentuado da suite MCI do que os envelopes de variação das rochas arqueanas e fanerozóicas. Em segundo, o padrão médio dos ETR das suítes AP e AC está contido no envelope de variação dos ETR dos basaltos tholcíticos arqueanos dos tipo TH2 de Condie (1981), mostrada pela área sombreada da figura 13. Nos basaltos tipo TH2 os ETRL são mais fracionados (e.g. Condie 1981) e, por sua vez, contém o

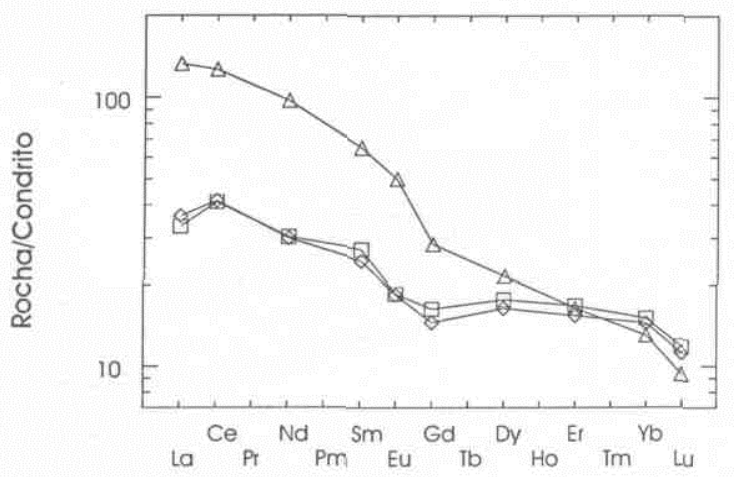

$\diamond$ Anfibolito Paraopeba $\square$ Anfibolito Candeias

$\Delta$ Metadiabásio Conceição de Itaguá

Figura 11 - Padrão geoquímico da composição média dos elementos de terras raras de três gerações de diques máficos do Complexo Metamórfico Bonfim Setentrional, normalizados pêlos valores de Masuda et al. (1973). Figure 11 • Chondrite normalized REE pattern for the three Northern Bonfim Metamorphic Complex mafic dykes (values from Masuda et al. 1973).

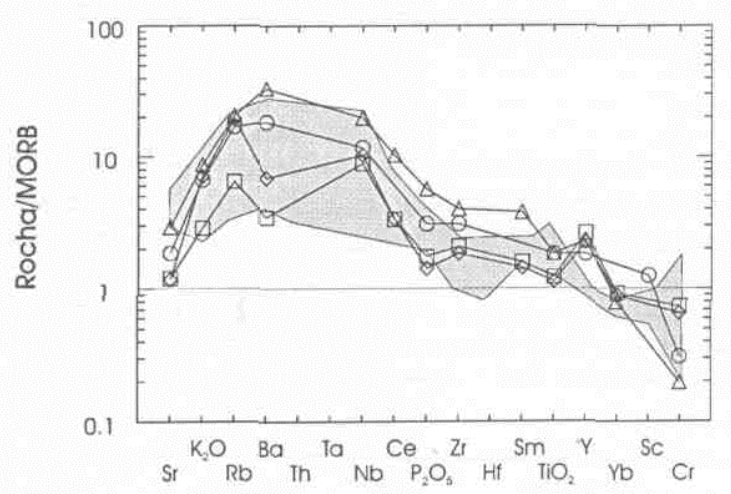

O Anfibolito Paraopeba

D Anfibolito Candeias A Metadiabásio Conceição de Itaguá

O Diabásio Santa Cruz

Figura 12 - Padrões geoquímicos médios das quatro gerações de diques máficos do Complexo Metamórfico Bonfim Setentrional comparados com o envelope de variação dos padrões geoquímicos dos basaltos modernos intraplacas (área sombreada; adaptado de Pearce 1982, 1983, Pharaoh \& Pearce 1984).

Figure 12 - MORB normalized eleiiient abundance for the Northern Bonfim Metamorphic Complex mafic dykex compared witli envelope range (shaded) ofmodern wiihinplate basalts (valuesfrom Pearce 1982; 1983; Pharaoh \& Pearce 1984).

envelope de variação dos ETR dos basaltos tholeiíticos cálcio-alcalinos modernos (área hachurada na figura 13), onde também se situam as amostras das suites AP e AC. Finalmente, a razão Ti/Zr (Fig. 9) configura duas tendências marcantes nas quatro gerações de diques máficos do CMBS. Uma é constituída pelas amostras das suites AP e AC, com razões 


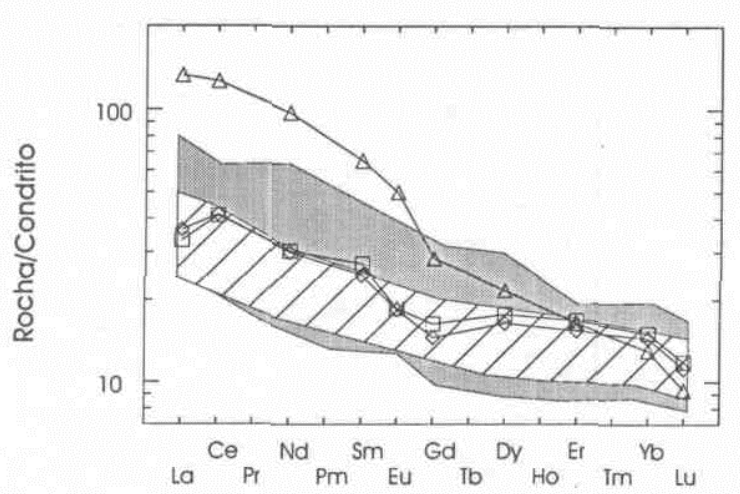

$\diamond$ Anfibolito Paraopeba

$\Delta$ Metadiabásio Conceição de Itaguá
Figura 13 - Padrões geoquímicos médios dos elementos de terras raras de três gerações de diques máflcos do Complexo Metamórfico Bonfim Setentrional comparados com os envelopes de variação dos padrões de terras raras dos basaltos arqueanos do tipo 77/2 (área sombreada) e basaltos modernos (área hachurada) do tipo cálcio-alcalino (valores de Condi e 1981).

Figure 13 - Chondriie normalized REE paliem for lhe Northern Bonfim Metamorphic Complex mafic dykes compared witli envelope rances of tlie Archean 77/2 (shaded) and modern calc-alkaline (hatched) basalts. The fields arefwm Condie (J98J).
$\mathrm{Ti} / \mathrm{Zr}$ menores e todas localizadas no campo dos basaltos modernos do tipo MORB. Este campo está, por sua vez, sobreposto aos dos basaltos dos arcos vulcânicos (AIB) e intraplaca (WPB) modernos. Outra é constituída pelas suites MCI c DSC, com razões Ti/Zr mais elevadas e cujas amostras se situam no campo dos basaltos intraplaca modernos.

Diante disto, é possível traçar algumas inferências gerais sobre a natureza petrotcctônica das quatro gerações de diques estudados. Em primeiro lugar, os diques mais jovens (MCI e DSC), tem várias características em comum e foram colocadas na crosta sob um mesmo ambiente tectônico, muito semelhante aos ambientes intraplaca modernos. Estas duas suites derivam, aparentemente, de fontes mantélicas enriquecidas. A suite DSC é, possivelmente, de idade Mesozóica. Em segundo lugar, os diques mais antigos (AP e AC) têm as características dos basaltos arqueanos e a sua natureza geoquímica indica uma fonte comum, do tipo N-MORB, como mostram as razões relativas a diversas fontes mantélicas da Tabela 6 e como indicam os valores de $\mathrm{Nd}(\mathrm{t})$ das rochas destas suites (ver Tabela 2), comparáveis com manto empobrecido ao longo do tempo (t), da ordem de $+1,7$ (para $t=3120$ Ma) c $+1,9$ (para 1=2900 Ma). Na suite AP, no entanto, as razões $\mathrm{K} / \mathrm{P}$ e Sr/Rb (Tabela 6), de acordo com Harte et al. (1989), Scymour \& Kumapareli (1995) e Thompson et al. (1984), sugerem uma fonte contaminada ou contaminação por crosta continental.

No contexto tectônico, as gerações de diques representam sucessivos episódios extensionais da crosta siálica. A primeira geração, representada pela suíte AP, estaria associada a um reservatório magmático (pluma?) de características geoquímicas do tipo N-MORB, subjacente à crosta continental já formada, oriundo de uma fonte mantélica profunda, como indicada pela sua natureza mais primitiva e pelo seu $\varepsilon_{\mathrm{Nd}}(\mathrm{t})$

Tabela 6 - Razões de elementos traços em basaltos, crosta continental, condrito (valores de Seymour \& Kumarapeli 1995) e diques máficos do Complexo Metamórfico Bonfim Setentrional. Símbolos: GDS - Sistema de Diques de Greenville; OIB - Basalto de Ilhas Oceânicas; AP -Anfibolito Paraopeba; AC-Anfibolito Candeias; MCI-Metadiabásio Conceição de Itaguá; DSC - Diabásio Santa

\section{Cruz.}

Table 6 - Trace elements ratios oftlte continental crust. basal t. chondrite (values from Seymoitr \& Kiniiarapeli J 995) and Northern Bonfim Metamorphic Complex mafic dykes. Keys: GDS - Greenville Dyke Swarmx; OIB - Ocean Islands Basalts; AP - Ainphibolite Paraopeba; AC - Amphibolite Candeias; MCI -Metadiabase Conceição de Itaguá; DSC - Diabase Santa Cria.

\begin{tabular}{|ccccccccccc|}
\hline & N-MORB & P-MORB & Condrito & $\begin{array}{c}\text { Crosta } \\
\text { Contincntal* }\end{array}$ & GDS & OIB & AP & AC & MCI & DSC \\
\hline $\mathrm{Zr} / \mathrm{Y}$ & $2-4$ & $04-06$ & 2,2 & $3,7-8,7$ & $4 \mathrm{e} 8$ & $3,2-5,4$ & 2,5 & 2,4 & 5,2 \\
$\mathrm{Zr} / \mathrm{Nb}$ & 230 & -10 & 19,5 & 76 & $10 \mathrm{e} 22$ & $13,8-21$ & 4,6 & 6,8 & 5,4 & 9,5 \\
$\mathrm{Sr} / \mathrm{Rb}$ & 127 & 23 & 33,7 & $3,1-43,5$ & $5-25 \mathrm{e} 100$ & $4,5-33,3$ & 4,7 & 12,9 & 15,9 & 11,3 \\
$\mathrm{~K} / \mathrm{Rb}$ & 1046 & 414 & 343 & 250 & $200 \mathrm{e} 880$ & $175-900$ & 254 & 292 & 313 & 336 \\
$\mathrm{Ba} / \mathrm{Nb}$ & 1,5 & 11 & 19,7 & $22-25$ & $2 \mathrm{e} 20$ & $01-45$ & 4,1 & 2,6 & 10,2 & 14,5 \\
$\mathrm{~K} / \mathrm{Ba}$ & 109 & 34 & 17,4 & $18,6-51$ & $20 \mathrm{e} 75$ & $10-185$ & 66,3 & 61,0 & 18,3 & 62,1 \\
$\mathrm{Dy} / \mathrm{Yb}$ & - & - & 1,57 & 1,6 & - & $1,6-2,1$ & 0,67 & 0,61 & 0,8 & - \\
$\mathrm{Sc} / \mathrm{Zr}$ & - & - & 1,55 & $0,06-0,5$ & - & $0,13-0,45$ & - & - & - \\
$\mathrm{Yb} / \mathrm{Zr}$ & - & - & 0,04 & $0,01-0,03$ & - & $0,02-0,03$ & 0,01 & 0,01 & 0,003 \\
$\mathrm{Sc} / \mathrm{Yb}$ & - & - & 38 & $5-16,4$ & - & $5,2-16,8$ & - & - & - \\
$\mathrm{Zr} / \mathrm{Hf}$ & - & - & 34 & -33 & - & $37-43$ & - & - & - \\
$\mathrm{V} / \mathrm{Nb}$ & 50 & $20-65$ & - & $2,4-47,5$ & $10 \mathrm{e} 100$ & $10-100$ & 7,7 & 11,5 & 3,5 \\
$\mathrm{~K} / \mathrm{P}$ & - & - & - & - & $1,5-40$ & - & 13,5 & 4 & 3,6 \\
$\mathrm{La} / \mathrm{Nb}$ & - & - & - & $>1,5$ & $0,7-2,3$ & 1,5 & 0,12 & 0,13 & 0,19 \\
$\mathrm{Nb} / \mathrm{U}$ & $47 \pm 10$ & - & - & $9-21^{*}$ & $01-07$ & $47 \pm 10$ & - & - \\
$\mathrm{Ti} / \mathrm{Yb}$ & - & - & - & - & $3000-5000$ & - & 1242 & 1150 & 2423 \\
\hline
\end{tabular}

${ }^{*}$ Crosta inferior 
positivo. Como mencionado, as rochas da suite AC guardam uma relação tectônica com plutonismo cálcio-alcalino, responsável pela suíte TS. Especulamos que este plutonismo de arco magmático, ao ascender para níveis superiores da crosta siálica arqueana, poderia levar consigo frações do magma máfíco, o qual estaria representado na segunda geração de diques arqueanos, originando a suite AC. Cabe notar que, isotopicamente, a suite AC se distingue da suite AP pela assinatura de $\mathrm{Nd}$, ilustrada pêlos valores de ENd modelados sucessivamente para $\mathrm{t}=\mathrm{T}_{\mathrm{DM}}$ e $\mathrm{t}=2780 \mathrm{Ma}$ (Tabela 2). Esta distinção responderia pela própria evolução do material mantélico no tempo, com extração em dois episódios distintos, um antecedendo (AP) o arco magmático do evento tectono-termal Rio das Velhas (2780-2700 Ma) e outro geneticamente ligado (AC). Esta interpretação está de acordo com a semelhança química das duas suítes. Já o metamorfismo dá suíte AC seria concomitante à colocação na crustal, devido à sua associação temporal com a fase magmática félsica responsável pela geração da suite TS (Carneiro et al. 1997).

As razões de $\mathrm{Zr} / \mathrm{Y}$ (Tabela 6) indicam que suítes $\mathrm{MCI}$ e DSC seriam oriundas de um manto enriquecido (P-MORB) e colocadas no Paleoproterozóico e possivelmente no Mesozóico, respectivamente. A colocação da suite MCI, em particular, é correlacionável ao enxame de diques de Lavras, datado em $1975 \pm 7$ Ma. Estudos geoquímicos e isotópicos $(\mathrm{Nd}, \mathrm{Sr})$ detalhados nestes diques sugerem, a exemplo da suite MCI, derivação de uma fonte enriquecida (Pinese, 1997).

$\mathrm{O}$ conjunto de dados geológicos, geoquímicos e isotópicos revelam, assim, uma distinção genética entre as duas suites básicas arqueanas (ambiente distensivo) e a MCI, a qual derivou de um manto enriquecido, e as são coerentes com os modelos que advogam uma mudança geodinâmica interna do planeta entre o Arqueano e o Paleoproterozóico, resultante do acoplamento do manto superior à crosta. Em decorrência, haveriam condições para fusão parcial e formação de magmas com características mais enriquecidas (litosféricas), como se sugere para a origem da suite MCI.

Tectonicamente, esta suite está ligada à evolução do arco magmático Mineiro (Teixeira et al. 1996), o qual foi acompanhado de plutonismo granítico e alcalino, representantes da orogenia Transamazônica (Noce et al. 1997). Posteriormente, as rochas da suite MCI foram submetidas a rejuvenescimento isotópico do sistema K-Ar (ca. $1000 \mathrm{Ma}$ ), por processos extensionais responsáveis pela formação da bacia de sedimentação do SGSF.

Agradecimentos Ao CNPq, FAPEMIG, CPGeo/USP, CPQ/DEGEO/EM/UFOP, GEOLAB/GEOSOL pelo apoio financeiro de laboratório. À Beatriz Baeta Mol (CEEL) e Rinaldo Afrânio Fernandes pela editoração e confecção de desenhos. A H. A. Nalini Jr. pela leitura crítica do manuscrito e V. T. S. Martins pela modelagem isotópica. Aos dois revisores anónimos pelas críticas e sugestões que muito contribuíram para clareza deste artigo. Este artigo é produto das atividades dos projetos FAPESP (95/4652-2), CNPq (523486/96-4) e FAPEMIG (Cex 856/96).

\section{MÉTODOS ANALÍTICOS Geocronologia K-Ar}

As análises K-Ar foram realizadas no CPGeo/USP de acordo com os procedimentos descritos por Amaral et al. (1966) e modificações posteriores. As análises de K, em duplicata, foram realizadas por ataque químico convencional e sua quantificação obtida por fotometria de chama em aparelho Micronal, modelo B-262. O argônio foi extraído em unidades de ultra alto-vácuo, sob pressões inferiores a 1 x $10^{-7} \mathrm{mmHg}$, com purificação em fornos de $\mathrm{Cu}-\mathrm{CuO}$ e titânio.

A análise isotópica do argônio foi realizada em espectrômetro de massa de fonte gasosa Nuclide, tipo Reynolds, empregando-se alíquotas de Ar puro, em quantidades mensuráveis, da ordem de $1 \times 10^{-5}$ ccSTP. A reprodutibilidade analítica é da ordem de 2 a $3 \%$, com base na repetição de padrões internacionais. $\mathrm{O}$ cálculo das idades utilizou as constantes recomendadas por Steiger \& Jaeger (1978): $\mathrm{X}^{40} \mathrm{~K}_{\beta}=$ $4962 \times 10^{-10}$ anos $^{11} ; \lambda^{40} \mathrm{~K}_{\text {total }}=0,581 \times 10^{-10}$ anos $^{-1}$; $\left({ }^{40} \mathrm{Ar} /{ }^{39} \mathrm{Ar}\right) \mathrm{atm}=295,5 \mathrm{e}{ }^{40} \mathrm{~K}=0,01167 \%$ Ktot.

Geocronologia Sm-Nd As análises $\mathrm{Sm}-\mathrm{Nd}$ foram realizadas no CPGeo/USP empregando a técnica de das colunas de resina de troca iônica e de pó de teflon HDEHP-coated, e de diluição isotópica (Sato et al. 1995). As leituras foram efetuadas em espectrômetro de massa VG-354. Os brancos laboratoriais de $\mathrm{Nd}$ e $\mathrm{Sm}$ forneceram valores máximos de 7 e $30 \mathrm{pg}$, respectivamente. A média de valores ${ }^{143} \mathrm{Nd} /{ }^{144} \mathrm{Nd}$ para os padrões La Jolla e BCR-1 são, respectivamente: 0,511849 $\pm 0,000025(l \sigma)$, e 0,512662 $\pm 0,000027(1 \sigma)$. Para os cálculos da idade modelo [TDM] utilizaram-se das constantes e parâmetros de DePaolo (1981), a saber: $a=0,25 ; b--3 ; c-8,5$. e a razão $\mathrm{Nd} / \mathrm{Nd}=0,7219$ para normalizar as razões ${ }^{143} \mathrm{Nd} /{ }^{144} \mathrm{Nd}$ (Chur)o $=0,512638$ e ${ }^{147} \mathrm{Sm} /{ }^{44} \mathrm{Nd}$ (Chur)o = 0,1967 . Os valores de $\varepsilon N d$ foram calculados usando a equação simplificada $\varepsilon N d(\mathrm{~T})=\varepsilon N d(0)-\mathrm{Qf} \mathrm{Sm} / \mathrm{Nd} \mathrm{T}$, assumindo o valor de CHUR (0) acima e QNd = 15,09.

Análises químicas As análises químicas de rocha total foram realizadas no GEOLAB/Geosol com amostras em duplicata para o controle de resultados. Os métodos empregados foram os seguintes: Fluorescência de Raios-X após por fusão da amostra com tetraborato de $\mathrm{Li}$, para determinação de $\mathrm{Al}$, $\mathrm{Ca}$, e Fe(total), Si, Mg, P, Cr e Ti; Fluorescência de Raios-X (pó prensado) para $\mathrm{Ba}, \mathrm{Cl}, \mathrm{Cs}, \mathrm{S}, \mathrm{Nb}, \mathrm{P}, \mathrm{Rb}, \mathrm{Sr}, \mathrm{Y}$ e $\mathrm{Zr}$; Ábsorção Atómica para $\mathrm{K}, \mathrm{Mg}, \mathrm{Mn}, \mathrm{Na}$ e $\mathrm{Pb}$; Espectrografia Óptica para $\mathrm{Zn}, \mathrm{Cu}, \mathrm{Co}$, Sc, Ni e V; Titulação com permanganato de $\mathrm{K}$ para $\mathrm{Fe}^{2+}$; Espectrometria de Plasma para os ETR. Os erros analíticos estimados são da ordem de $1 \%$ na Fluorescência de Raios-X (fusão), 5\% na Fluorescência de Raios $\mathrm{X}$ (pó prensado), 3\% na Absorção Atômica e 5\% na Espectrografia Óptica e Especlrometria de Plasma.

\section{REFERÊNCIAS}

Amaral, G.; Cordani, U. G.; Kawashita, K. \& Reynolds, J. H. 1966. Potassium argon dates of basaltic rocks from Southern Brazil. Geochimica Cosmochimica /U7a, 31:117-142.

Baer, G. \& Heimann, A. 1995. Physics and chemistiy ofDykes. Rotterdam, Balkema. $520 \mathrm{p}$.

Beswick, A. E. \& Soucie, G. 1978. A correction procedure for metassomatism in an Archean Greenstone Belt. Precambrian Research, 6:235-248.

Carneiro, M. A. 1991. Petrography and Geochemistry of dykes from the northern Bonfim Metamorphic Complex, Minas Gerais, Brazil. Boletim IG-USP, 10:59-62 (Publicação Especial).

Carneiro, M. A. 1992. O Complexo Metamóifico Bonfim Setentrional (Quadrilátero Ferrifero, Minas Gerais): Litoestratigrafia e Evolução Geológica de um Segmento de Crosta Continental do Arqueano. São Paulo, 233p. Tese de Doutoramento, Instituto de Geociências da Universidade de São Paulo.
Carneiro, M. A. \& Teixeira, W. 1993. Geoquímica e geocronologia dos diques máficos Precambrianos do Complexo Metamórfico Bonfim Setentrional, região meridional do Craton do São Francisco, Brasil. In: Semana de Geoquímica, IX; Congresso Geoquímico dos Países de Língua Portuguesa, II, Porto, 1993. Memórias... Porto, p. 15-16.

Carneiro, M. A.; Jordt-Evangelista, H. \& Teixeira, W. 1997. Eventos Magmáticos Arqueanos de Natureza Cálcio-Alcalina e Tholeíitica no Quadrilátero Ferrífero e suas Implicações Tectônicas. Revista Brasileira de Geociências, 27(1): 123-131.

Carneiro, M. A.; Teixeira, W.; Carvalho Júnior, I. M. de \& Fernandes, R. A. 1998. Ensialic tectonic setting of the Archean Rio das Velhas greenstone belt: $\mathrm{Nd}$ and $\mathrm{Pb}$ isotopic evidence from the Bonfim Metamorphic Complex, Quadrilátero Ferrífero, Brazil. Revista Brasileira de Geociências, (no prelo). 
Chaves, A. de O. \& Correia Neves, J. M. 1995. Diques máficos Proterozóicos do Complexo Granito-Gnáissico-Migmatítico da Porção Meridional do Craton do São Francisco, MG. In: Simpósio de Geologia de Minas Gerais, 8, Diamantina, 1995. Anais. Diamantina, SBG/NMG. p. 55-57.

Condie, K. C. 1981. Archean greensíone belts. Amsterdam, Elsevier. 434p.

Condie, K. C. 1985. Secular Variation in the Composition of Basalts: an Index to Mantle Evolution. Journal of Pelrology, 26:545-563.

Condie, K.C. 1989. Geochemical changes in basalts and andesites across the Archean-Proterozoic boundary: Identification and significance. Lithos, 23:1-18.

Condie, K. C. 1990. Geochemical characteristics of Precambrian basaltic greenstones. In: Hall, R. P. \& Hughes, D. J. (Eds.), Early Precambrian Basic Magmatism. Glasgow, Blackie. p. 40-55.

Condie, K. C. 1997. Sources of Proterozoic mafic dyke swarms: constraints from $\mathrm{Th} / \mathrm{Ta}$ and $\mathrm{La} / \mathrm{Yb}$ ratios. Precambrian Research, 81:3-14.

Condie, K. C.; Bobrow, D. J. \& Card, K. D. 1987. Geochemistry of Precambrian Mafic Dykes from the Southern Superior Province of the Canadian Shield. In: Halls, H. C. \& Fahrig, W. (Eds.), Mafic Dyke Swarms. St. John's. G. A. C. p. 95-108.

Couto, J. G. P.; Teixeira, W. \& Cordani, U. G. 1983. Considerações sobre as principais épocas de fraturamento do Craton do São Francisco com base em datações K-Ar em rochas básicas. In: Simpósio Geologia de Minas Gerais, 2. Belo Horizonte, 1983. Anais...Belo Horizonte, SBG/NMG. p. 38-49.

Cox, K. G.; Bell J. D. \& Pankhurst, R. J. 1979. The Interpretation of lgneous Rocks. London, George Allen \& Unwin. $450 \mathrm{p}$.

De La Roche, H.; Leterrier, J.; Grandclaude, P. \& Marchai, M. 1980. A classification of volcanic and plutonic rocks using R1 R2-diagram and major-element analyscs - Its relationships with current nomenclatura. Chemical Geology, 29:183-210.

DePaolo, D. J. 1981. A neodymium and strontium isotopic study of the Mesozoic calc-alkaline granitic batholiths of Sierra Nevada and Peninsular Ranges, Califórnia. Journal of Geophysical Research, 86:10470-10488.

Ernst, R. E.; Buchan, K. L. \& Palmer, H. C. 1995. Giant dyke swarms: characteristics, distribution and geotectonic applications. In: Bacr, G. \& Heimann, A. (Eds.) Physics and Cliemistry of Dykes. Rotterdam, Balkema. p. 3-21.

Floyd, P. A. \& Winchester, J. A. 1975. Magma type and tectonic setting discrimination using immobile elements. Earth and Planetary Science Letters, 27:211-21S.

Floyd, P. A. \& Winchester J. A. 1978. Identification and discrimination of altered and metamorphosed volcanic rocks using immobile elements. Chemical Geology, 21:291-306.

Guimarães, D. 1933. Os anfibolitos da região diamantífera do norte de Minas Gerais. Anais da Academia Brasileira de Ciências, 5(4):237-258.

Hall, R. P. \& Hughes, D. J. 1990. Early Precambrian Basic Magmatism. Glasgow, Blackie. 520 p.

Halls, H. C. \& Fahrig, W. 1987. Mafic Dyke Swarms. Geological Association of Canada, Special Paper no. 34. 520 p.

Hart, W. H.; Gabriel, W. G.; Waltcr, R. C. \& Mcrtzman, S. A. 1989. Basallic volcanism in Ethiopia: constraints on continental rifting and mande interactions. Journal of Geophysical Research, 94:7731-7748.

Irvine, T. N. \& Baragar, W. R. A. 1971. A Cuide to the Chemical Classification of the Common Volcanic Rocks. Canadian Journal of Earth Sciences, 8:523-548.

Lê Bas, M.; Lê Maitre, R. W.; Streckeisen, A. \& Zancttin, B. 1986. A chemical Classification of Volcanic Rocks Based on the Total Alkali-Silica Diagram. Journal of Petrology, 27:745-750.

Machado, N. \& Carneiro, M. A. 1992. U-Pb evidence of Late Archean tectonothermal activity in southern São Francisco shield, Brazil. Canadian Journal of Earth Sciences, 29:2341-2346.

Machado, N.; Shrank, A.; Noce, C. M. \& Gautthier, G. 1996. Ages of detrital zircon from Archean-Paleoproterozoic sequences: Implications for Greenstone Belt setting and evolution of a Tranzamazonian foreland basin in Quadrilátero Ferrífero, southeast Brazil. Earth and Planetary Sciences Letters, 141( 1-4):259-276.

Masuda A.; Nakamura, N. \& Tanaka, T. 1973. Fine structures of mutually normalized rare-earth pattern of chondrites. Geochimica et Cosmochimica Acta, 36:239-348.

Noce, C. M.; Teixeira, W.; Quéméneur, J. J. G.; Martins, V. T. S. \& Bolzachini, E. 1997. Isotope signatures of Paleoproterozoic granitoids from the Southern São Francisco Craton and implications for the evolution of the Transamazonian orogeny. Journal of South American Earth Sciences. Submetido, 1997.

Oliveira E. P. \& Knauer L. G. 1993. Corpos Máficos e Uitramáficos do Craton do São Francisco. In: Dominguez, J. M. L. \& Misi, A. (Eds.). O Craton do São Francisco. Salvador, SBG/SMG/CNPq. p 119-136.
Parker, A. J.; Rickwood, P. C. \& Tucker, D. H. 1990. Mafic Dykes and emplacement mechanisms. Rotterdam, Balkema. 541 p.

Pearce, J. A. 1982. Trace element characteristics of lavas from destructive plate boundaries. In: THORPE, R. S. (Ed.), Andesites. Orogenic andesites and related rocks. Chichester, J. Wiley \& Sons. p. 525-547.

Pearce, J. A. 1983. Role of the Sub-continental Lithosphere in Magma Génesis at Active Continental Margins. In: Hawkesworth, C. J. \&

Norry, M. J. (Eds.), Continental Basalts and Mantle Xenoliths. Nantwich, Shiva. p. 230-349.

Pearce, J. A. \& Cann, J. R. 1973. Tectonic setting of basic volcanic rocks determined using trace element analyses. Earth and Planetary Science Letters, 19:290-300.

Pharaoh, T. C. \& Pearce, J. A. 1984. Geochemical Evidence for the Geotectonic Setting of Early Proterozoic Metavolcanic Sequences in Lapland. Precambrian Research, 25:283-308.

Pinese, J. P. P. 1997. Geoqitímica, Geologia Isotóplca e Aspectos pé trol ógi cos dos Diques Máficos Pré-Cambrianos da Região de Lavras (MG), Porção Sul do Craton do São Francisco. São Paulo. 178 p. Tese de Doutoramento, Instituto de Geociências da Universidade de São Paulo.

Pinese, J. P. P.; Teixeira, W.; Qucmeneur, J. J. G.; Piccirillo, E. M.; Petrini, R. \& Bellieni, G. 1996. Archean Basic-Noritic Dykes in the Southern part of the São Francisco Craton: Geochemical and Geochronological Characteristics. In: Archaen Terranes of the South American Platform Symposium, Extended Abstracts ... Brasília, 1996, SBG. p.62.

Sato. K.; Tassinari, C. C. G.; Kawashita, K. \& Petronilho, L. 1995.0 método Geocronológico Sm-Nd no $1 \mathrm{G}-\mathrm{USP}$ e suas aplicações. Anais da Academia Brasileira de Ciências, 67(3):313-336.

Schorscher, H. D. 1991. Mafic dykes from southeastern São Francisco Craton, MG, Brazil. In: International Symposium on Mafic Dykes, 1. São Paulo, 1991. Extended Abstracts... São Paulo, SBG. p 87-88.

Seymour, K. S. \& Kumarapeli, P. S. 1995. Geochemistry of the Greenville Dyke Swarm: role of plume-source mantle in magma génesis. Coiitributions to Mineralogy and Petrology, 120:29-41.

Silva, A. M.; Chemale Jr., F.; Kuyumjian, R. M. \& Heaman., L. 1995. Mafic Dike Swarms of Quadrilátero Ferrífero and Southern Espinhaço, Minas Gerais, Brazil. Revista Brasileira de Geociências, 25(2): 124-137.

Stillman, C. J. \& Williams, C. T. 1979. Geochemistry and Tectonic Setting of Some Upper Ordovician Volcanic Rocks in East an Southeast Ireland. Earth and Planetary Sciences Letters, 42:288-310.

Steiger, R. H. \& Jãeger, E. 1978. Subcomission on Geochronology: Convention on the use of Decay Constants in Geochronology a Comoschronology. Contributions to the Geologic Time Scale. Studies in Geology, 6:67-72.

Taylor, S. R. \& McLennan, S. M. 1985. The Continental Crust: Its Composition and Evolution. Oxford, Blackwell. 312 p.

Teixeira, W. 1989. Mafic dykes in the Southern part of the São Francisco Craton: Tectonic Review based on K-Ar geochronology. Boletim do Instituto de Geociências da USP, 20:25-27 (Série Científica).

Teixeira, W.; Carneiro, M. A.; Noce, C. M.; Machado, N.; Sato. \& Taylor, P. N. 1996. Pb, Sr and Nd isotope constraints on the Archean evolution of gneissic-granitoid complexes in the southern São Francisco Craton, Brazil. Precambrian Research 78:151 -164.

Teixeira, W.; Kawashita, K.; Pecchio, M. \& Tame, N. R. 1988. Geocronologia K-Ar do enxame de diques básicos da parte meridional do Craton do São Francisco e implicações no contexto geotectônico. In: Congresso Brasileiro de Geologia., 35. Belém, 1988. Anais... Belém, SBG. v. 6; p 2870-2886.

Thompson, R. N.; Morrison, M. A. Hendry, G. L. \& Parry, S. J. 1984. An assessment of the relative roles of acrust and mantle in magma génesis: an elemental approach. Philosophical Transactions of the Royal Society of London, 310:549-590. (S. A).

Watters, B. R. \& Pearce, J. A. 1987. Metavolcanic rocks of the La Ronge Domain in the Churchill Province, Saskatchewan: geochemical evidence fora volcanic are origin. In: Pharaoh, T. C; Beckinsale, R. D. \& Rickard, D. (Eds.), Geochemistry and Mineralization of Proterozoic Volcanic Suite. Oxford, Blackwell. p. 167-183 (Geological Society Special Publications, 33)

Winchester, J. A. \& Floyd, P. A. 1977. Geochemical discrimination of different magma series and their differentiation products using immobile elements. Chemical Geology, 20:325-343.

Manuscrito A-934 Recebido em 23 de setembro de 1997 Revisão dos autores em 25 de maio de 1998 Revisão aceita em 28 de maio de 1998 